[rV ص-ros]

$$
\begin{aligned}
& \text { تخفيض كلف الفشل باستخدام منهج الحيود السداسي }
\end{aligned}
$$

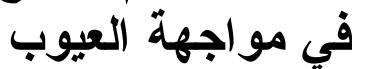

$$
\begin{aligned}
& \text { دراسة حالة في معمل الألبسة الولادية في الموصل } \\
& \text { علي حازم اليامور }
\end{aligned}
$$

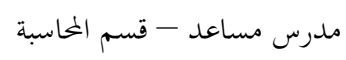

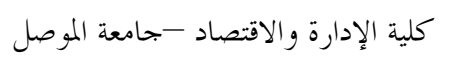

$$
\begin{aligned}
& \text { a.alihazim@yahoo.com }
\end{aligned}
$$

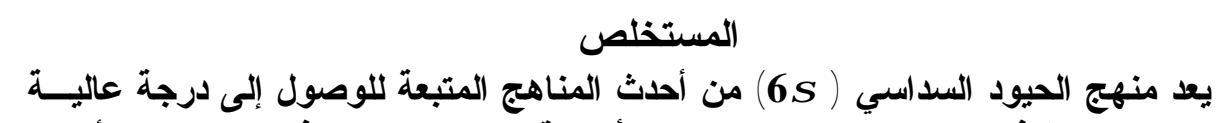

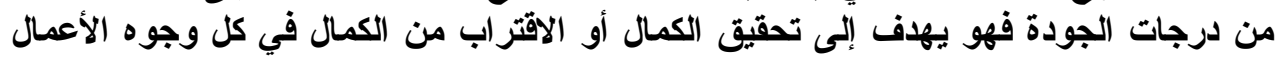

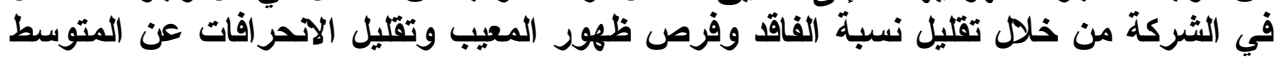

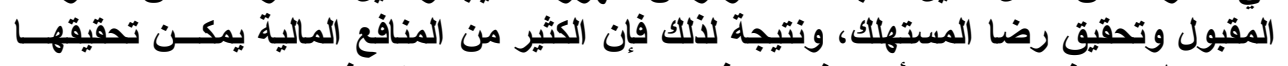

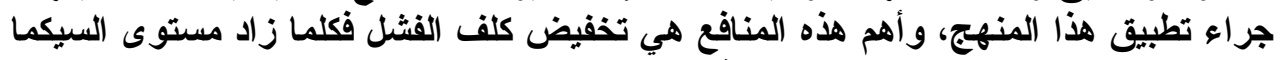

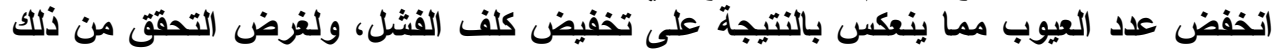

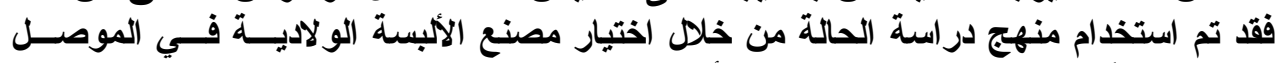

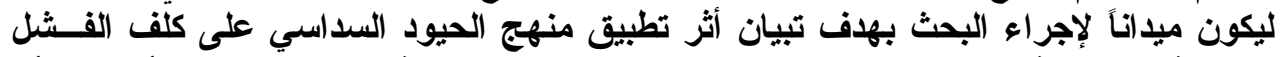

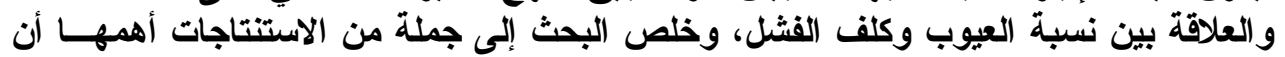

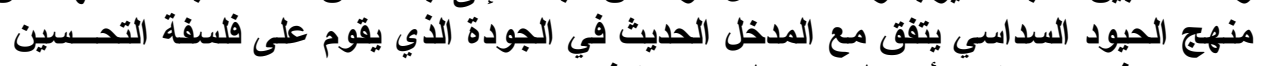

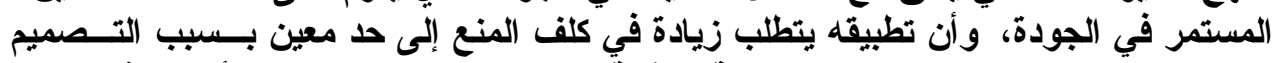

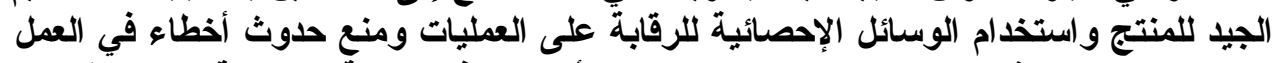

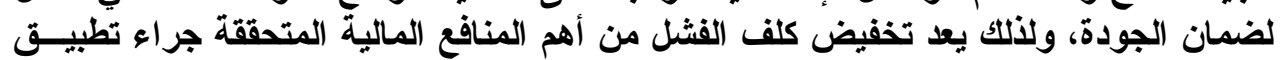

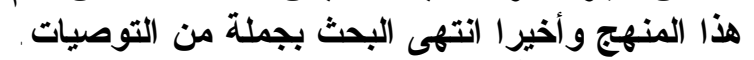
الكلمات المفتاحية: كلف الفشل، البهن الحيود السداسي. 


\title{
Reduce the Cost of Poor Quality Using the Six Sigma Approach in the Face of Defects: A Case Study in Children Wear Factory in Mosul
}

\author{
Ali H. Alyamoor \\ Assistant Lecturer \\ Department of Accountancy \\ University of Mosul
}

\begin{abstract}
The six sigma is of the latest approaches to reach the high degree of quality, it aims to achieve a perfect or near of perfection in all facets of business in the enterprise by reducing wastes and opportunities for the emergence of defect, reduce the distortions and achieve customer satisfaction. As a result of this, much of the financial benefits can be achieved by the application of this approach. The most important of these benefits is to reduce the cost of poor quality, increase the sigma level cause of decrease the number of defects. This leads to reduce the cost of poor quality, to certain from that may used the case study approach in Children Wear Factory at Mosul to be the area to conduct research to clarify the effect of the application of six sigma approach on the cost of poor quality. The relationship between the proportion of defects and the cost of poor quality in factory, the research found a number of conclusions that the most important of them, six sigma approach in line with the entrance of modern quality, which is based on the philosophy of continuous improvement in quality. The application requires an increase in the cost of prevention, because the good design of the product. The use of statistical methods to control processes, prevent errors in the work to ensure that quality and reduction the cost of poor quality. These are the most important financial benefits achieved by the application of this approach. The study also concluded several recommendations.
\end{abstract}

Key words: cost of poor quality, six sigma

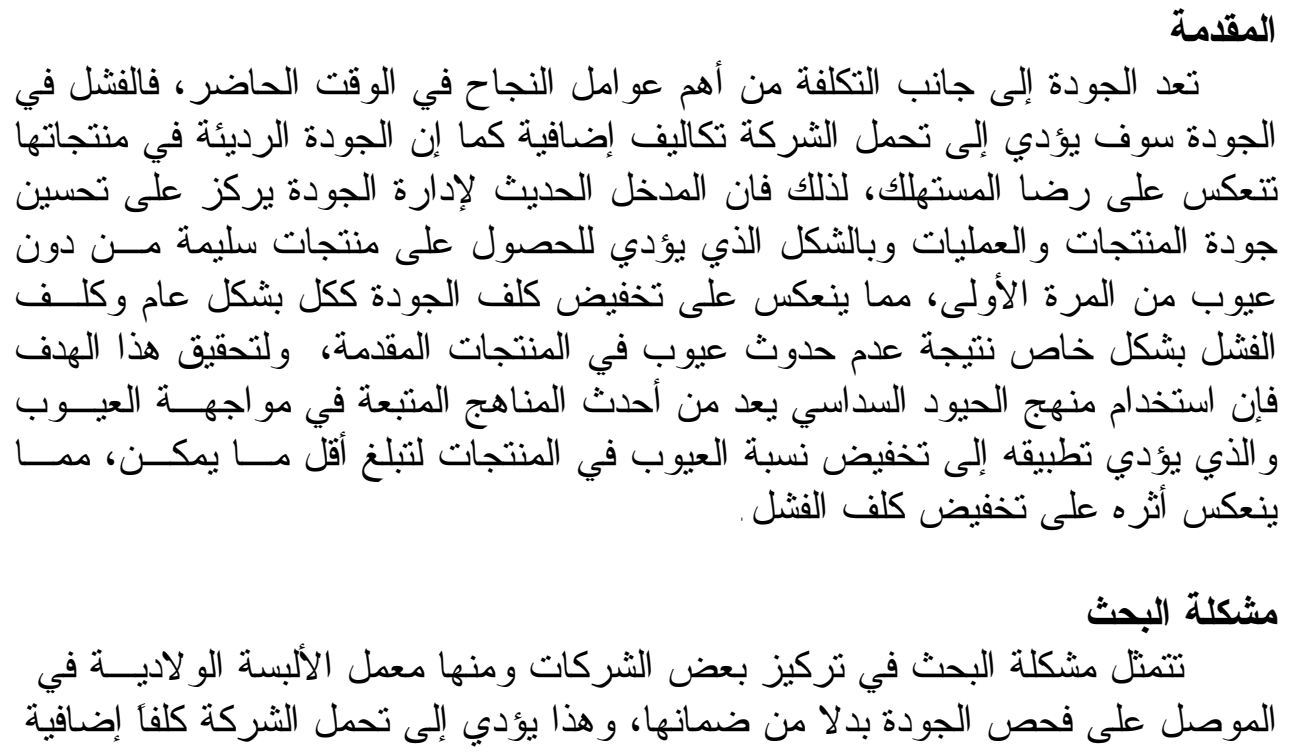


نتيجة الفشل في الهنتجات بسبب فثل الفحص في منع حدوث العيــوب فـي المنتجــات المقدمة.

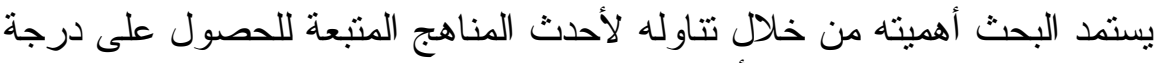

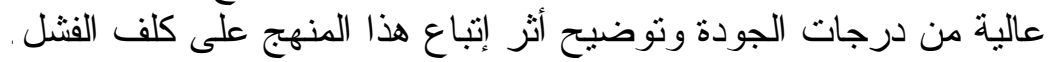

$$
\text { أما الأهداف التي يسعى البحث إلى تحقيقها فهي: }
$$

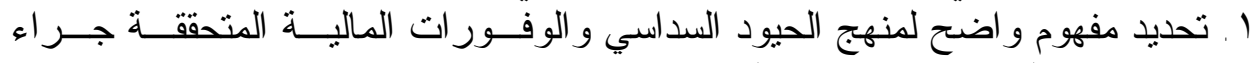

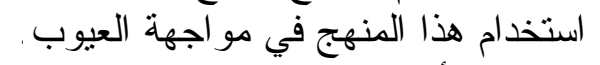

r ا توضيح أثر استخدام منهج الحيود السداسي على كلف الفشل و العلاقة بين مسستوى

$$
\text { الاتحر افت المعياري وكلف الجودة. }
$$

$$
\begin{aligned}
& \text { فرضية البحث } \\
& \text { يقوم البحث على الفرضية الآتية: } \\
& \text { إن استخدام منهج الحيود السداسي في مو اجهة العيوب وضمان الجودة يؤدي إلـى } \\
& \text { تخفيض كلف الفشل. }
\end{aligned}
$$

$$
\begin{aligned}
& \text { خطة البحث } \\
& \text { لغرض تحقيق هدف البحث فقد تم تقسيم البحث إلى: } \\
& \text { أولاً - الجانب النظري ويشمل النقاط الآتية: }
\end{aligned}
$$

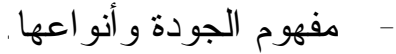

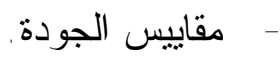

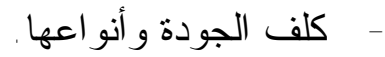

$$
\begin{aligned}
& \text { - - - مفهوم الحيود السداسي. } \\
& \text { - - المنهجيات المتعلقة بالحيود السداسي. } \\
& \text { - - المنافع المالية نتيجة لتطبيق منهج العين الحيود السداسي. } \\
& \text { - العلاقة بين كلف الفنشل ومنهج الحيود السداسي. }
\end{aligned}
$$


ثانياً - الجانب الميداني: در اسة حالة في معمل الألبسة الو لادية في الموصل ويشمل:

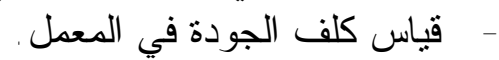

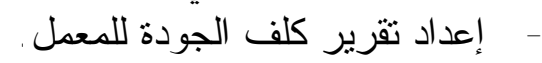

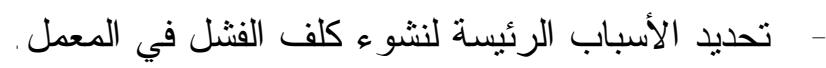

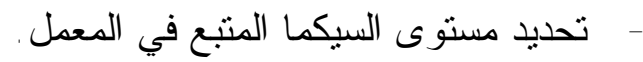

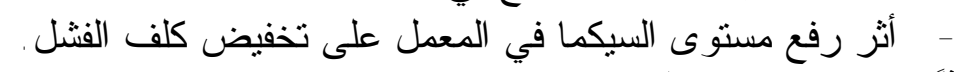
ثالثاً - الاستنتاجات و التوصيات.

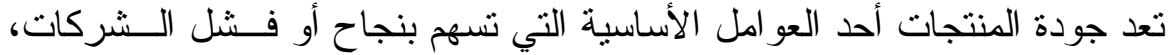

\section{أولاً - الجانب النظري

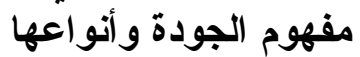

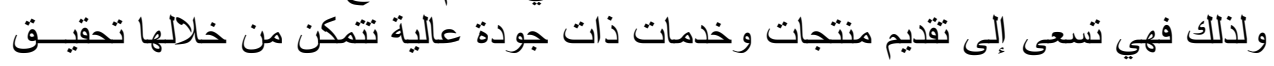

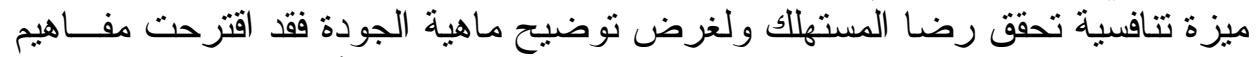

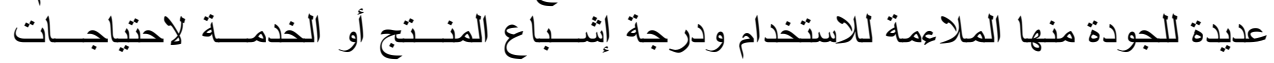

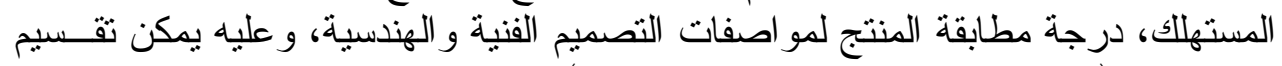

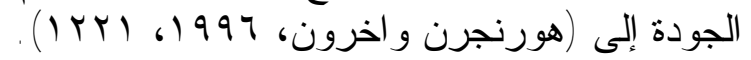

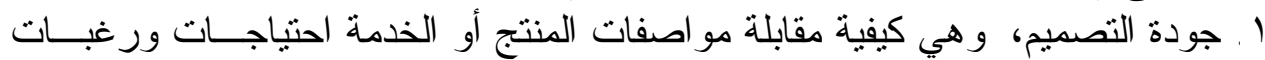

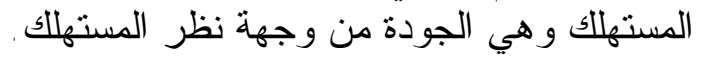

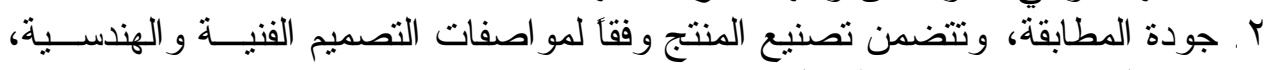

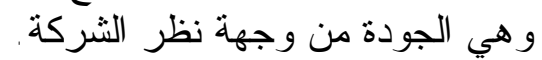

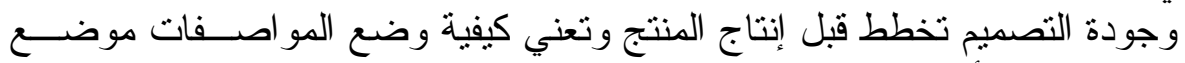

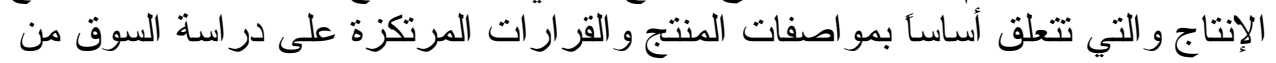

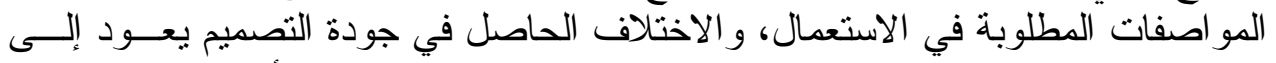

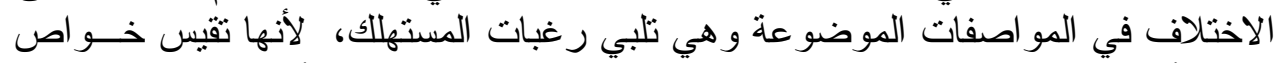

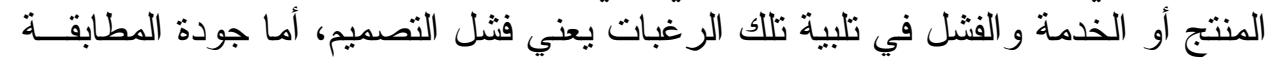

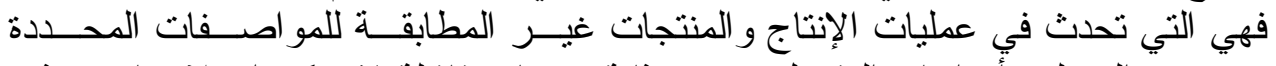

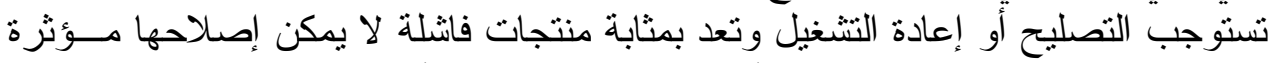

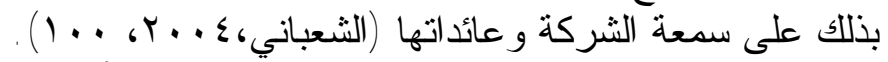

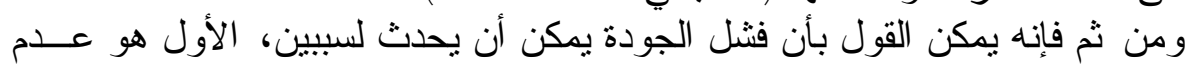

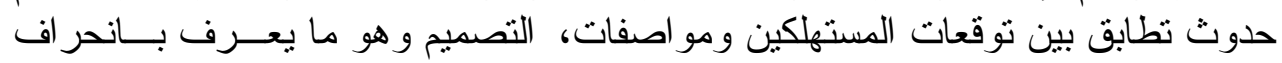

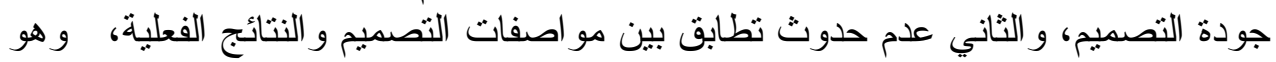

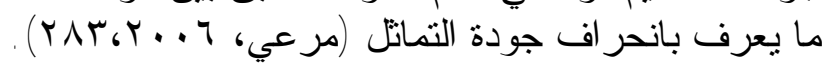

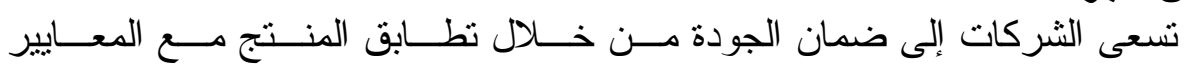

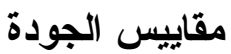

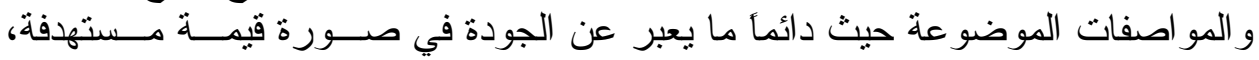

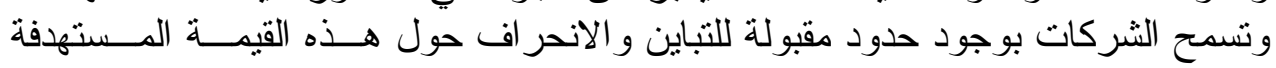


[ro9] اليامون

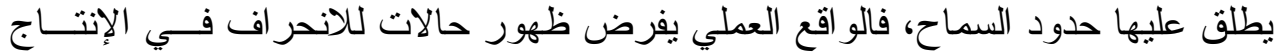

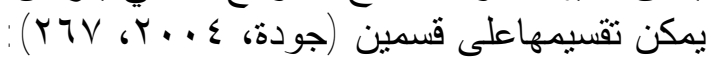

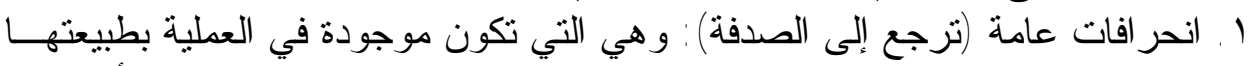

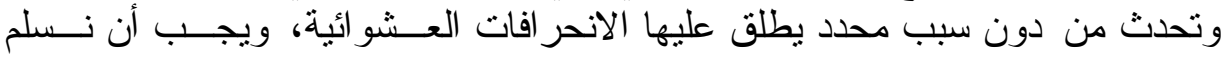

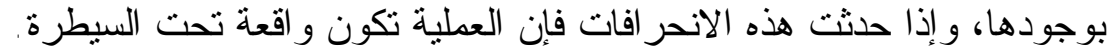

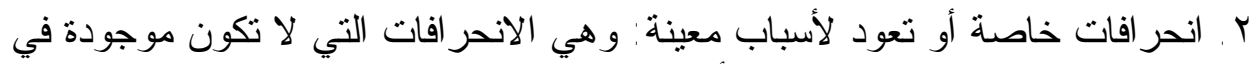

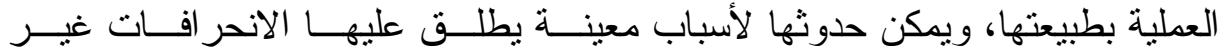

العثو ائية، و إذا حدثت مثل هذه الانحر افات فإن العان العملية تكون خار ج السيطرة.

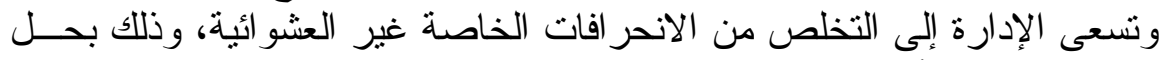

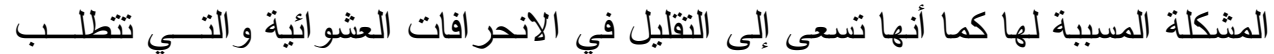

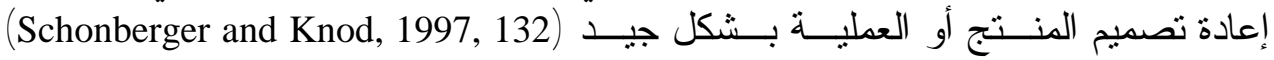
ومعرفة مستوى الانحر افات عن الجودة المستهدفة تتطلب استخدام مجموعة من من المقات المقاييس

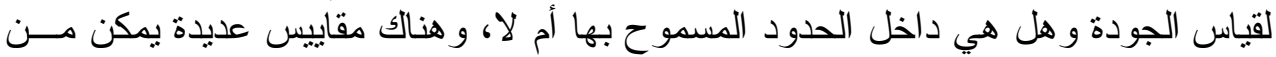

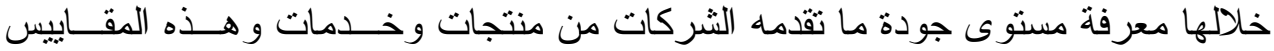

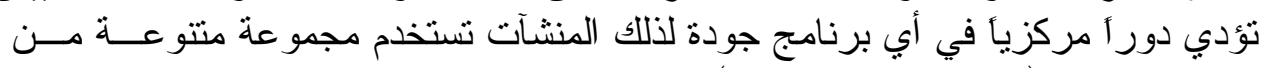

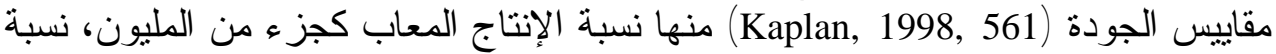

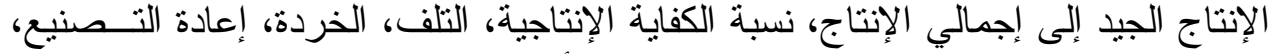

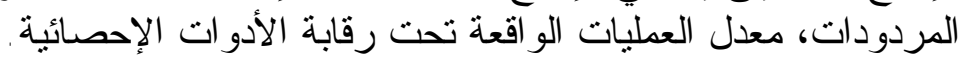

كلف الجودة وأنواعها

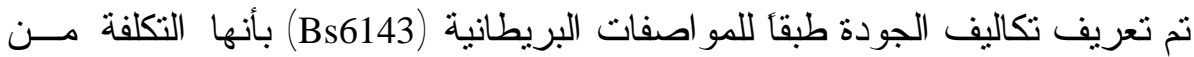

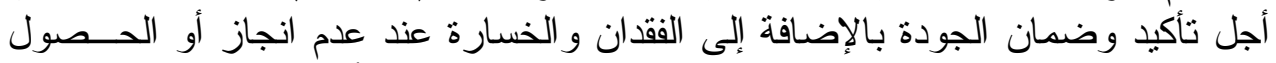

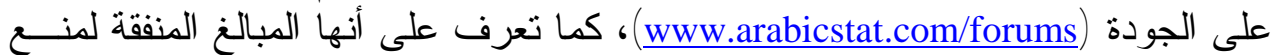

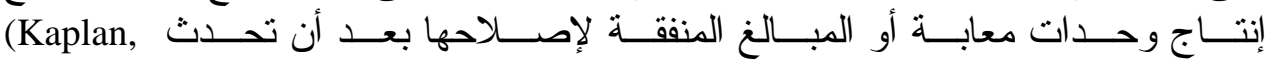

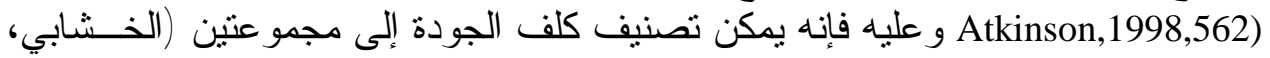
:(Vo, Y . . T

ا ـ كلف ضمان الجودة، وهي الكلف الناتجة عن رغبة المنشأة في التأكد من أن الأعمال

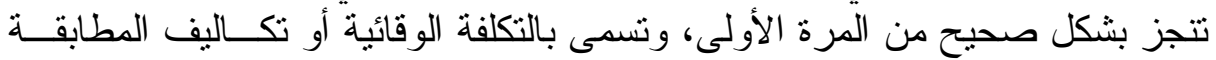
و وتقسم على تكاليف المنع وتكاليف التقييم.

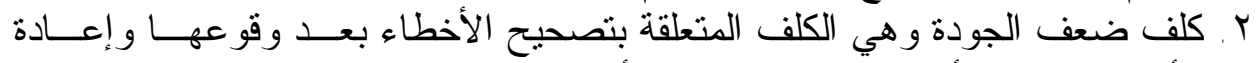

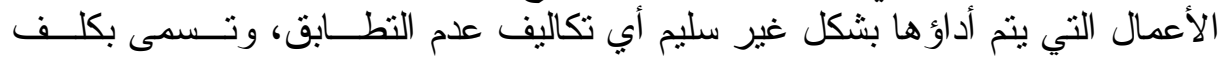

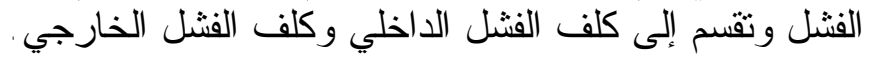

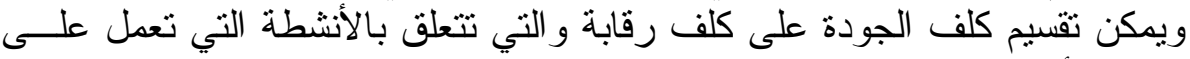

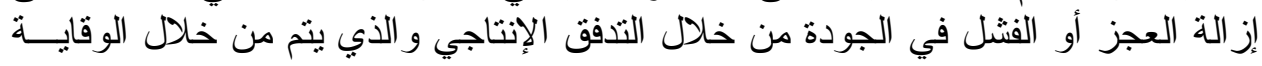

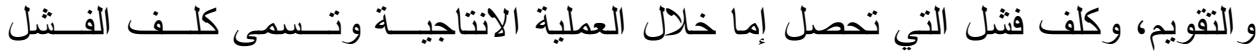

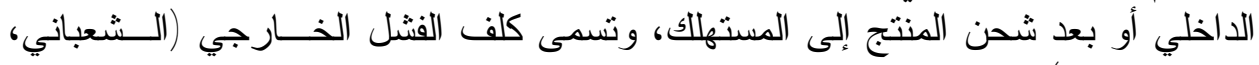

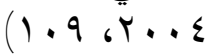

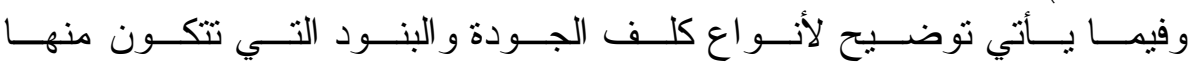

.(Davis and Heineke, 2003, 303) 
أولاً - كلف الوقاية: و هي التكاليف المرتبطة بمنع حدوث الجودة الرديئة التي عادة تتفــق

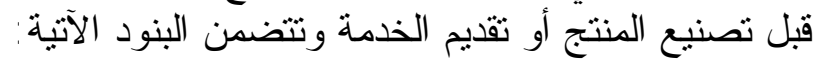

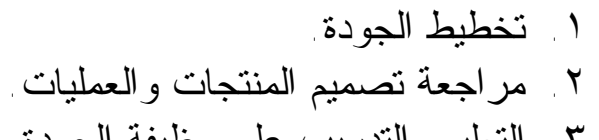

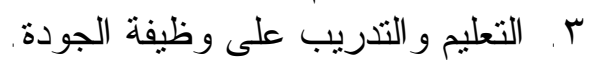
ع. ـ رقابة العطليات لتحقيق ملاعمة المنتج للاستخدام المحدد.

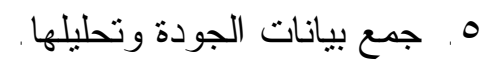
7 ا و إعداد تقرير كلف الجودة.

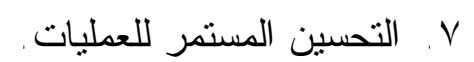

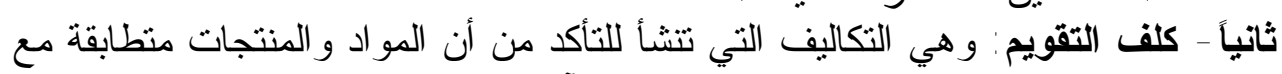
متطلبات الجودة المعيارية وتتضمن البنود الآتينة:

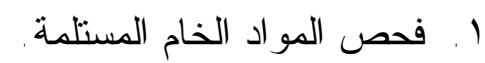
r. r. فحص المنتجات في نقاط مختلفة خلال الإنتاج. r. ب. فحص واختبار الهنتجات النهائية. ع. ـ تكاليف تدقيق ومر اجعة الجودة.

ثالثاً - كلف الفشل الداخلي: وهي تكاليف إنتاج منتجات رديئة يتم اكتثافها قبل وصـــولها إلى المستهلك وتتضن العن البنود الآتية:

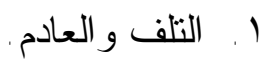

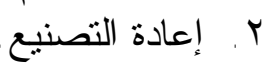

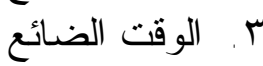

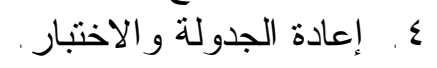

رابعاً - كلف الفثل الخــارجي: و هي التكاليف التي تحدث بعد وصول المنتجات الرديئــة

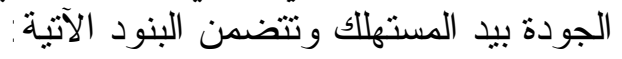

$$
\begin{aligned}
& \text { 1. ش شكاوي الزبائن. } \\
& \text { r. الضمان و الصيانة الزبائة بعد البيع. } \\
& \text { r. ب. المسموحات. }
\end{aligned}
$$

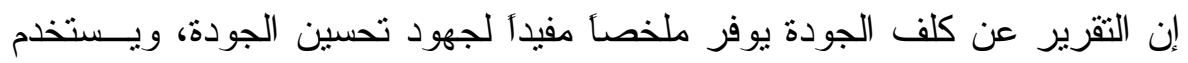

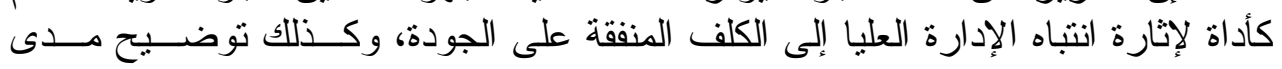

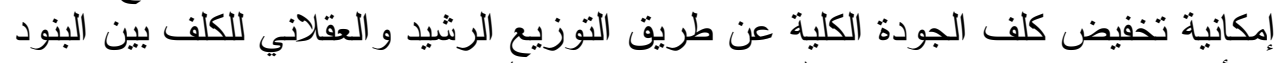

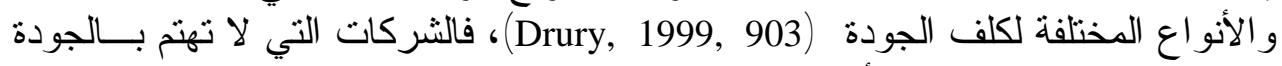

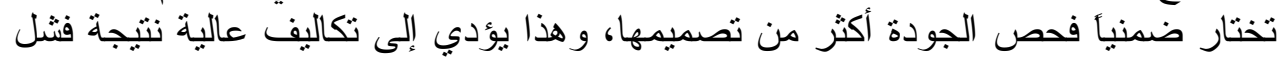

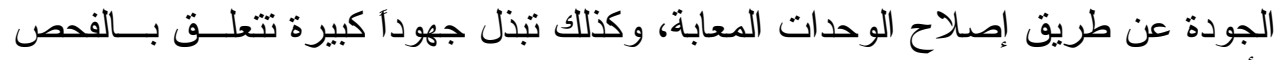

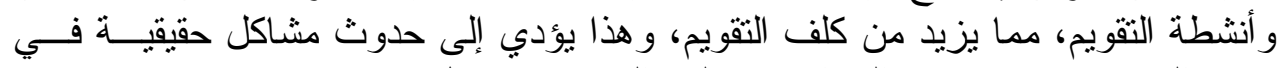

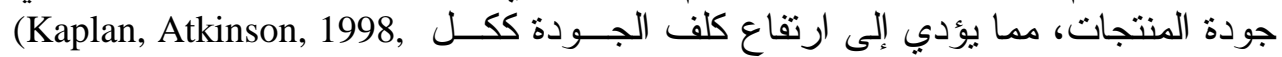

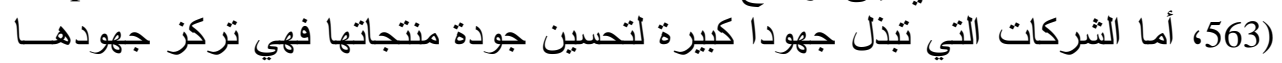

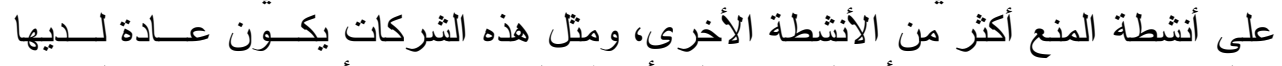

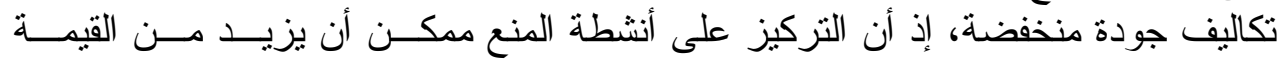




\section{اليامور] [rr]}

للمنتجات، وهذا يؤدي إلى تخفيض الحاجة إلى الفحص و أنشطة الفشل وبالـشـكل الـــي

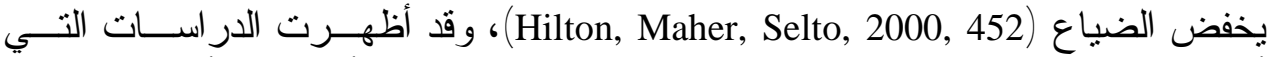

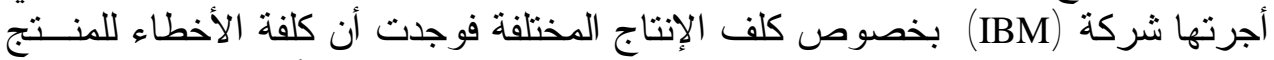

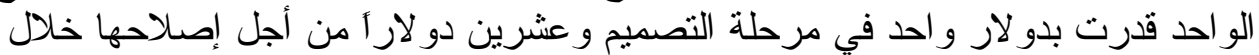

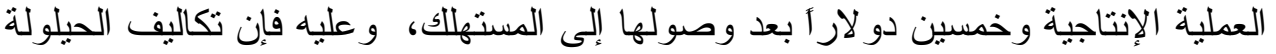

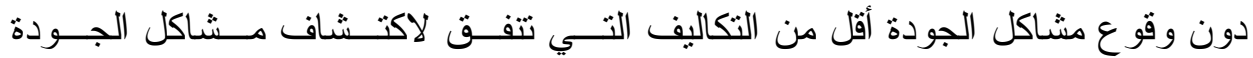

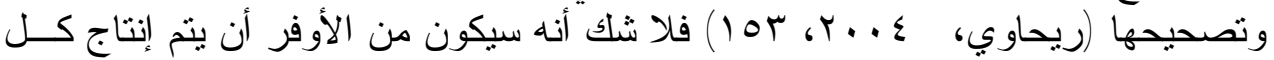

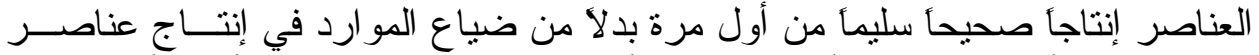

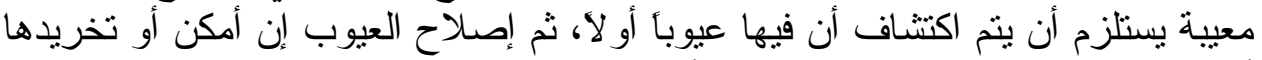

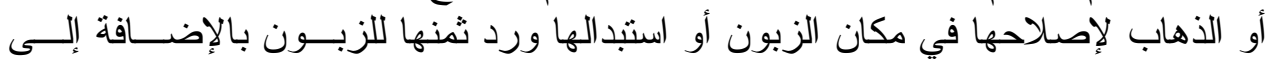

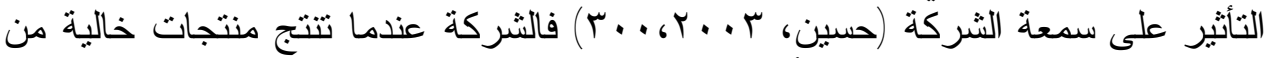

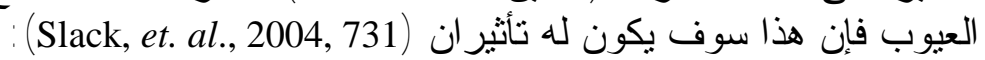

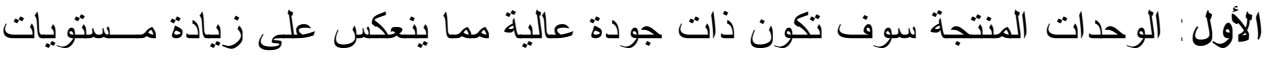
الطاقة (بسبب عدم إعادة إنتاجه).

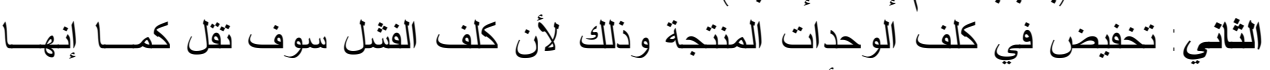

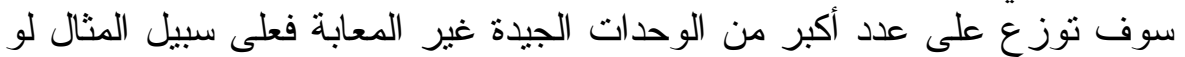

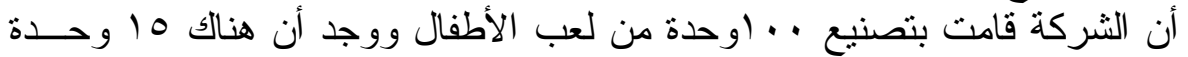

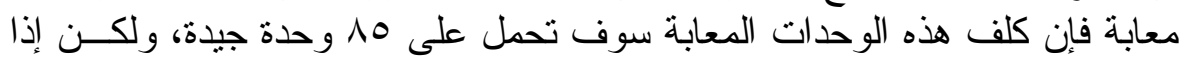

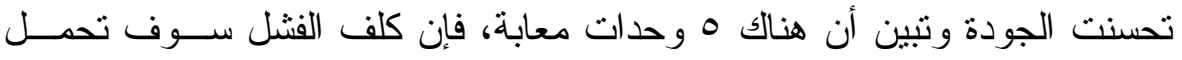
على 90 وحدة جيدة، مما يؤدي إلى خفض الى كلفة الوحدة الو احدة المنتجة .

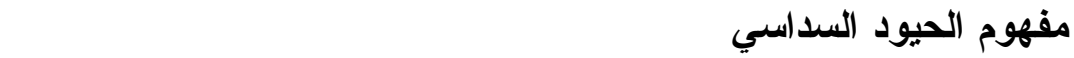

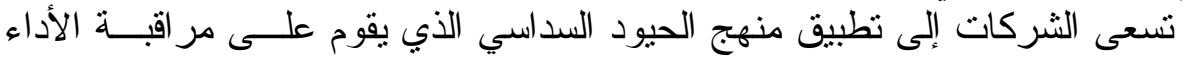

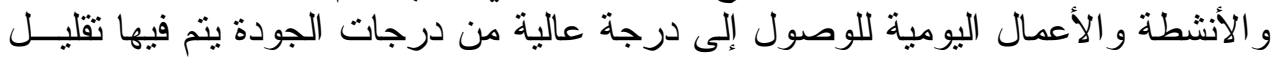

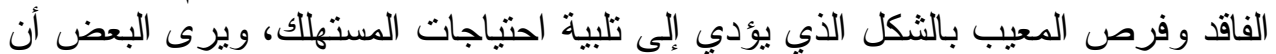

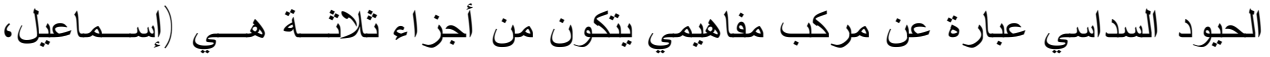
:() 11 , r. . T ا . مقياس إحصائي للأداء المتعلق بالعمليات وتصنيع المنتجات.

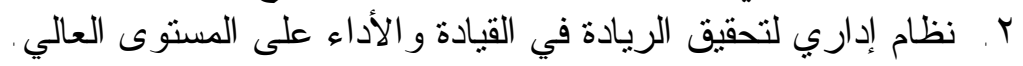

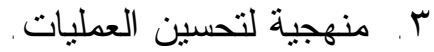

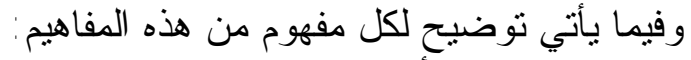

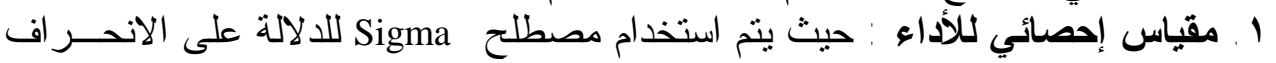

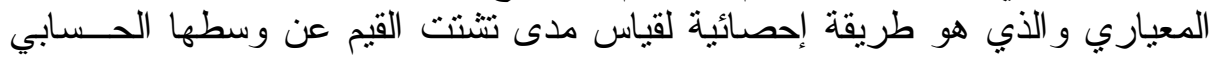

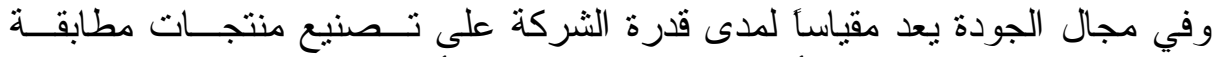

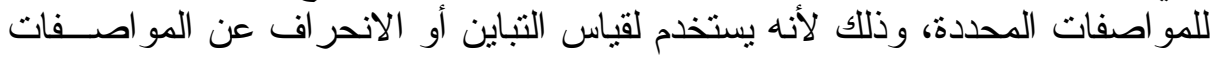

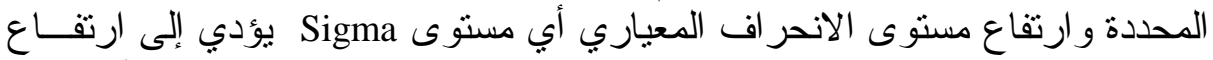

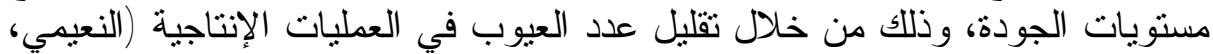

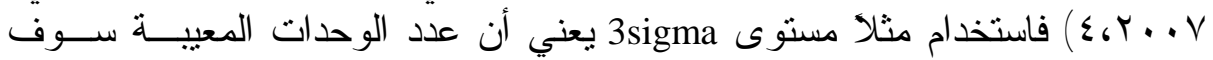




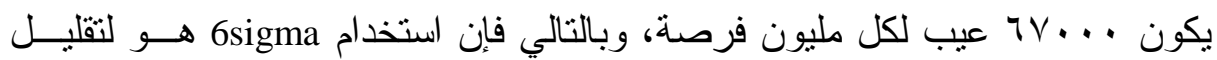

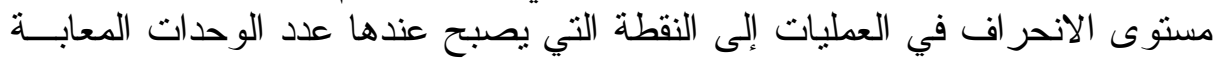

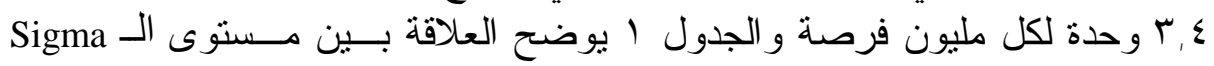

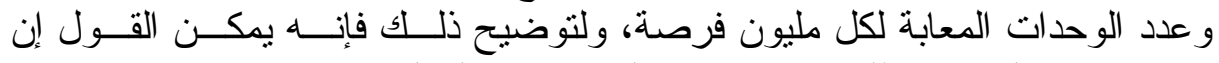

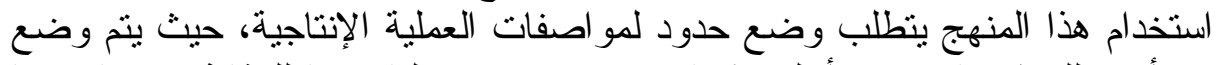

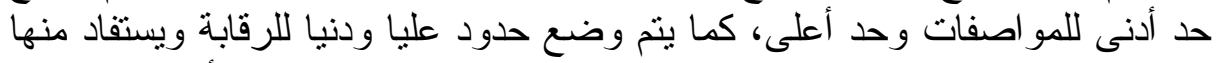

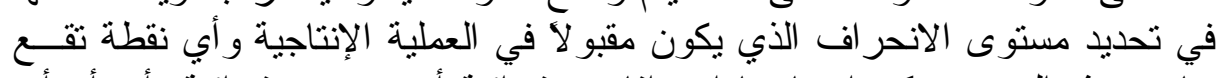

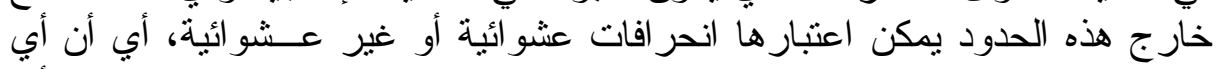

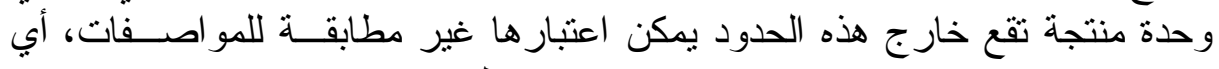

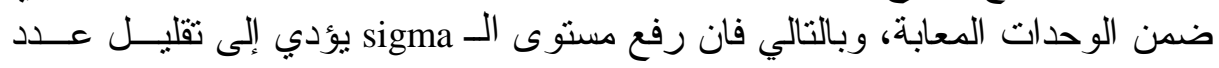
الوحدات التي تقع خارج هذه الحدود وبالتالي رفع مستويات رئت الجودة.

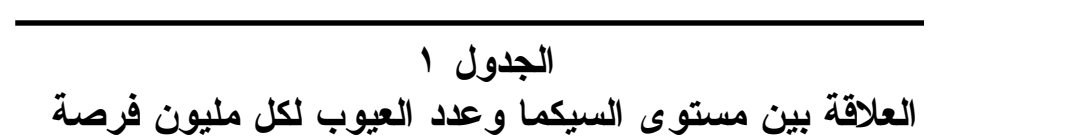

\begin{tabular}{|c|c|}
\hline 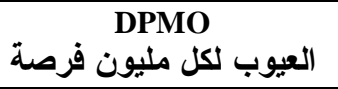 & $\begin{array}{l}\text { Sigma Level } \\
\text { ميتوى سيجما }\end{array}$ \\
\hline $7910 \ldots$ & 1 \\
\hline $0 \ldots .$. & 1,0 \\
\hline r.Ar.. & $r$ \\
\hline 10170. & $r, 0$ \\
\hline $7 V \ldots$ & $r$ \\
\hline TrV.. & $r, 0$ \\
\hline TYK. & $\varepsilon$ \\
\hline 1150. & $\varepsilon, 0$ \\
\hline TrT & 0 \\
\hline$r r$ & 0,0 \\
\hline$r, \varepsilon$ & 7 \\
\hline
\end{tabular}

(davis,aquilan,chas,2003,273)

ولغرض تحديد مستوى الـ Sigma في أي منشأة بتطلب الأمر إتباع مجموعة مــن فئن

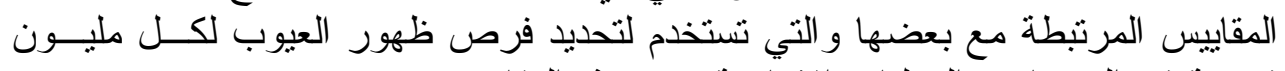
فرصة في المنتجات و العمليات الإنتاجية ومن هذه المقاييس (Slack, et. al., 2004, 625).

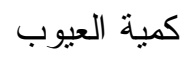

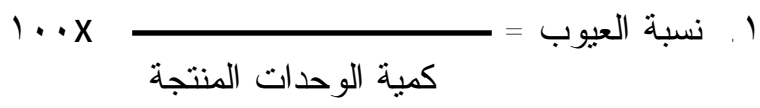

$$
\begin{aligned}
& \text { r ، نسبة الدقة في العمليات = } 1 \text { - نسبة العيوب }
\end{aligned}
$$

عدد العيوب

كمية الوحدات المنتجة X عدد فرص ظهور العيوب (عدد انواع العيوب) 
اليامور[r]

$$
\text { ع. . العيوب لكل مليون فرصة = العيوب لكل فرصة x ..... X }
$$

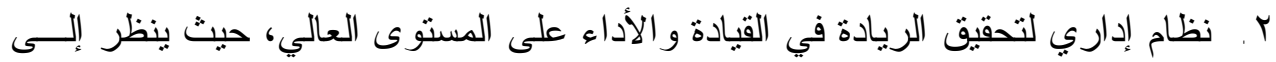

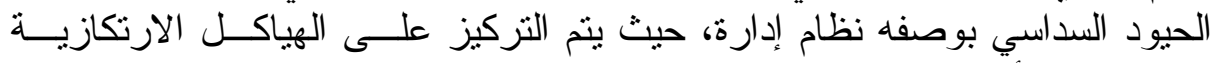

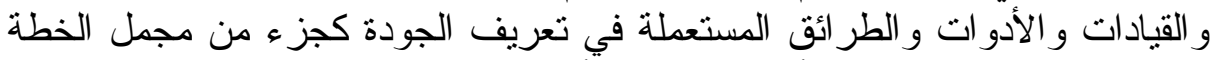

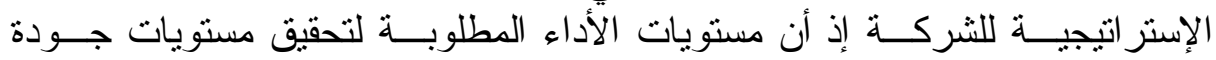

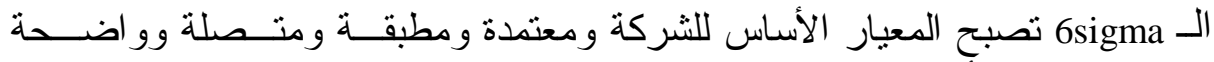

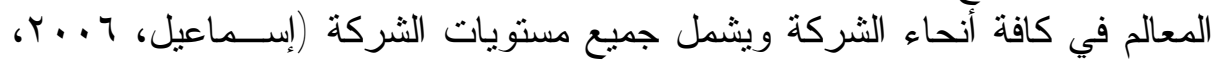

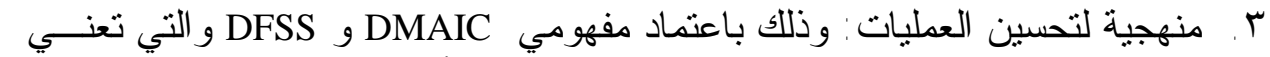

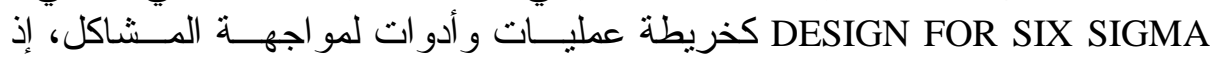

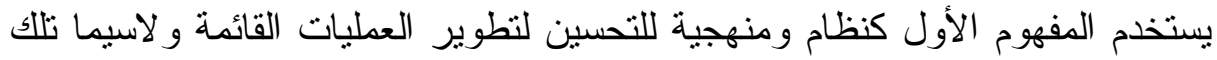

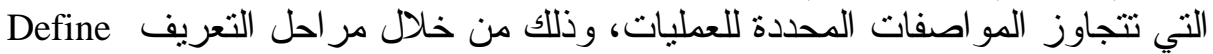

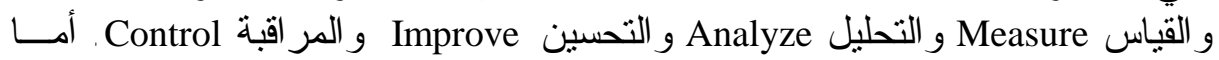

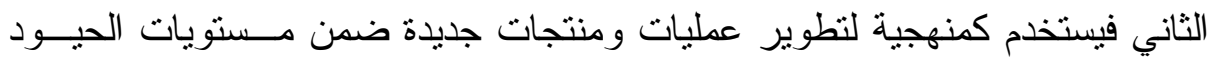

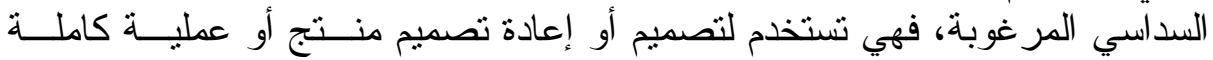

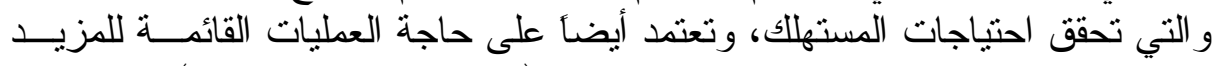

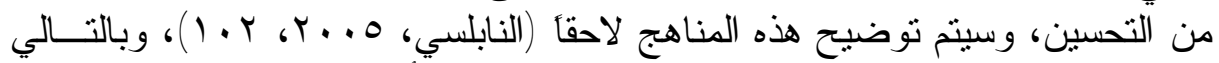

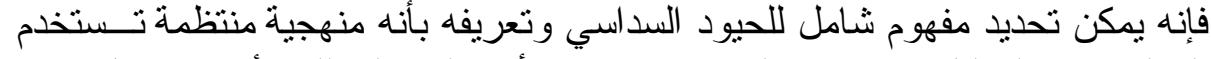

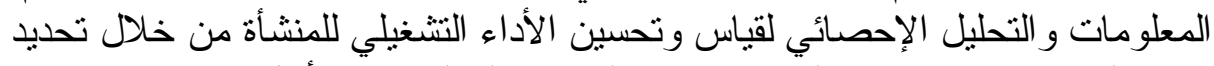

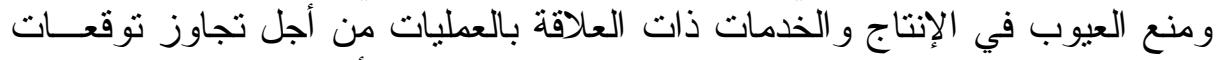

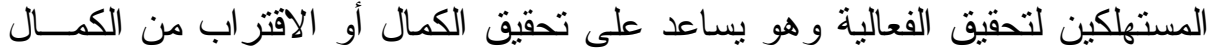

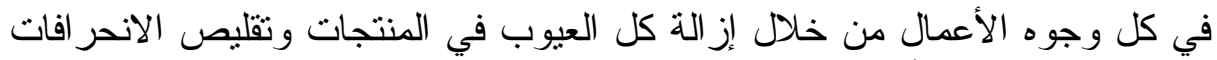

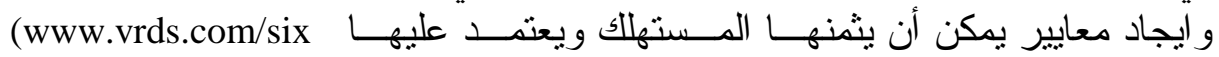
. sigma/dmaic )

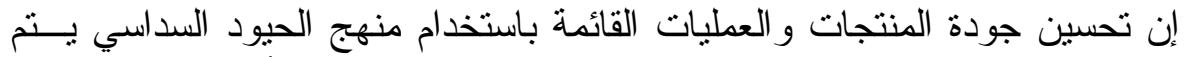

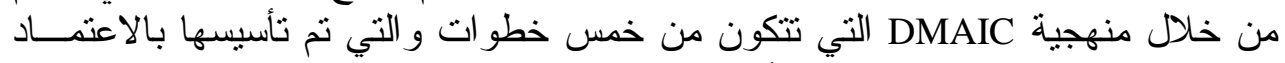

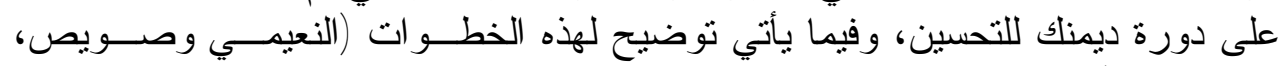

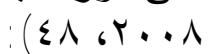

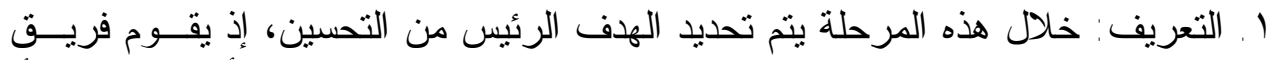

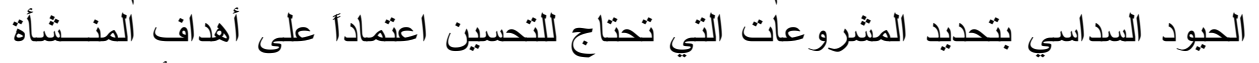

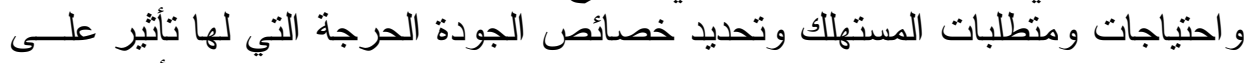

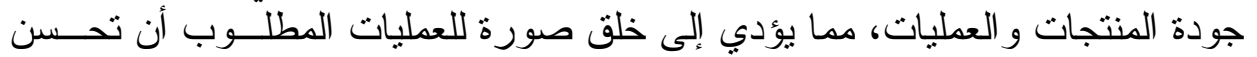

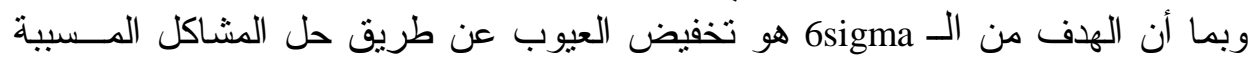

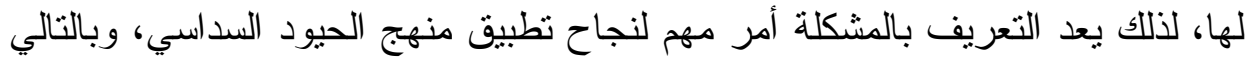


فالسبب الرئيس لهذه المرحلة التعريف بالمشكلة والتغير ات التي لها تأثير على المشكلة. http://www.realinnovation.com/content/c070319a.asp

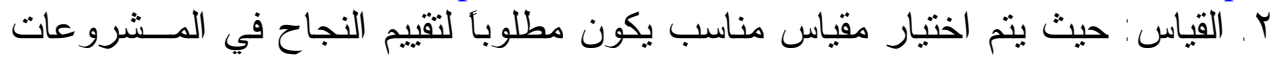

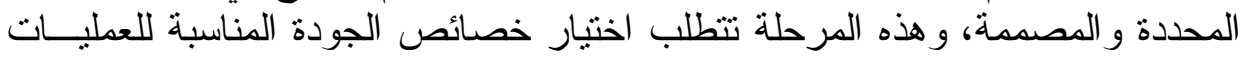

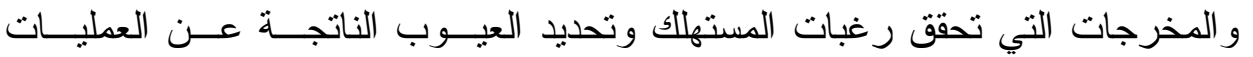

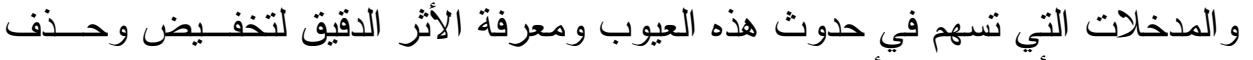

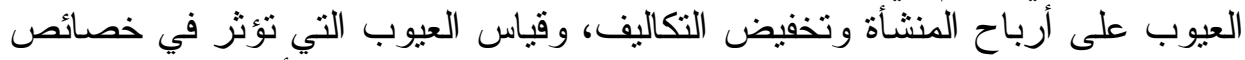

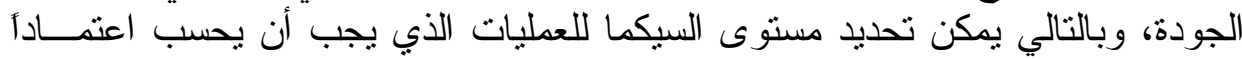

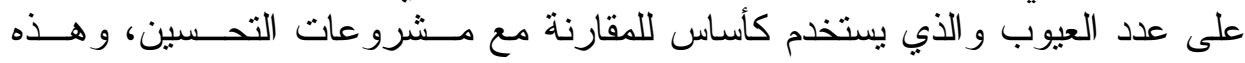

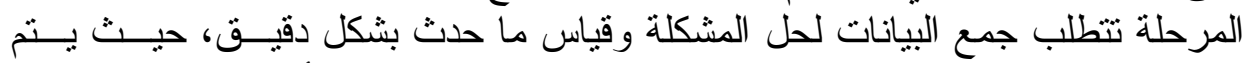

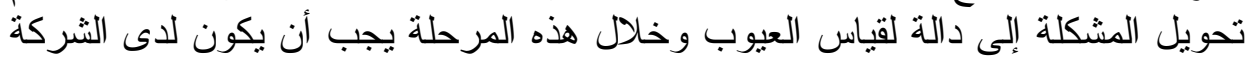

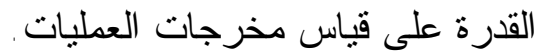

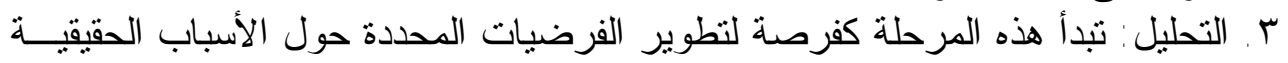

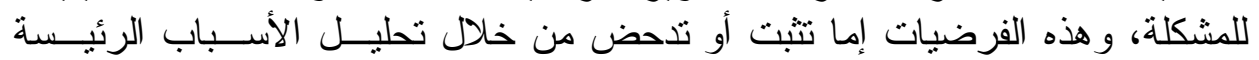

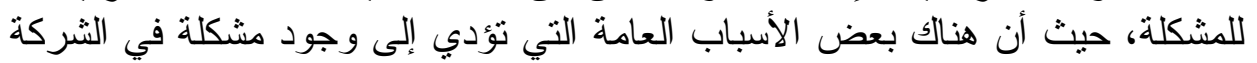

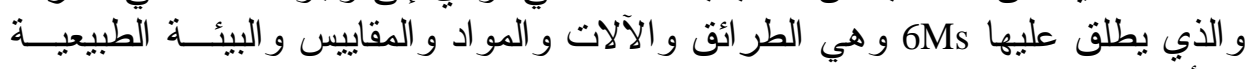

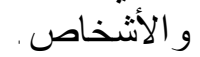

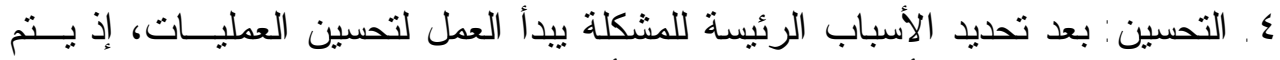

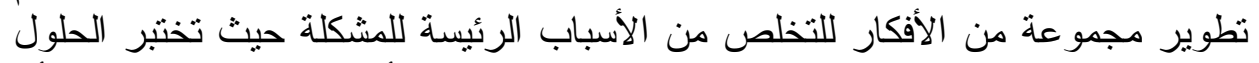

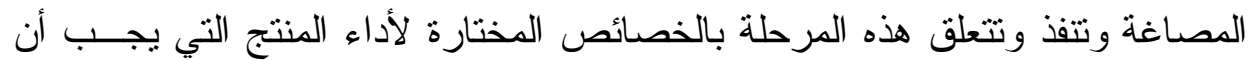

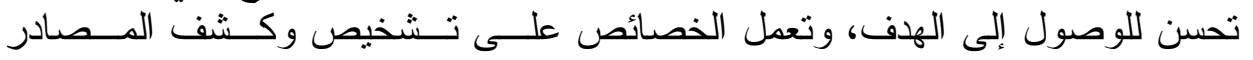

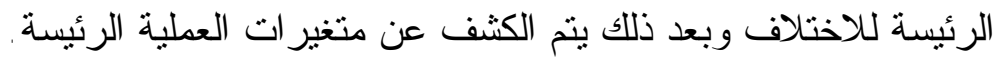

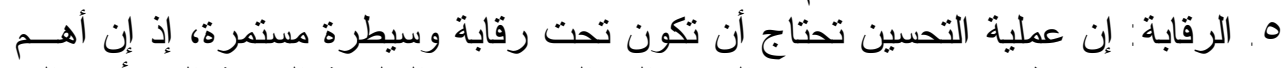

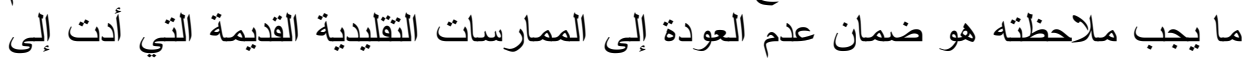

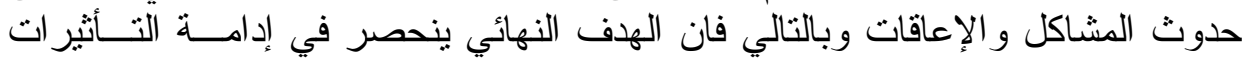

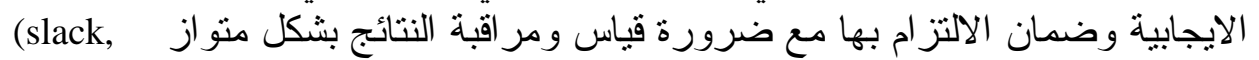
.et., al., 2004, 65)

أما عندما تكون هناللك حاجة إلى عمليات معينة لإعادة تصميم أو تصميم عمليـات التيات و ونتجات جديدة من البداية بهدف تخفيض العيوب و الحفاظ على على مستوى جودة عالية فئة فيتم

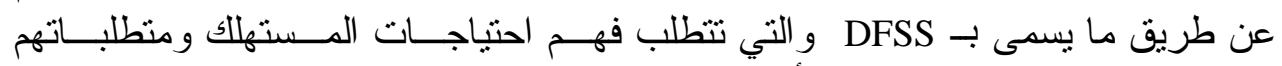

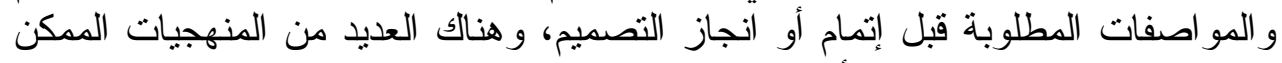

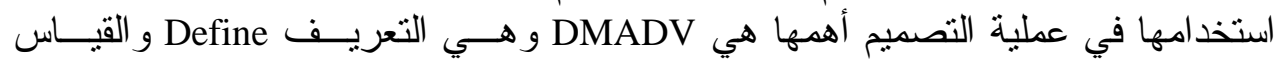
Measure

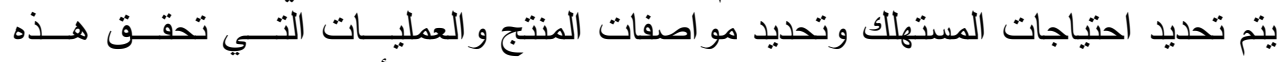

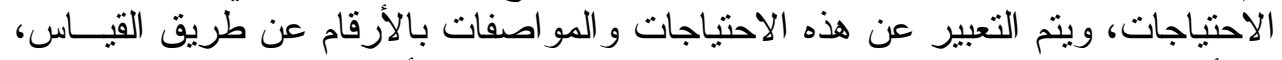

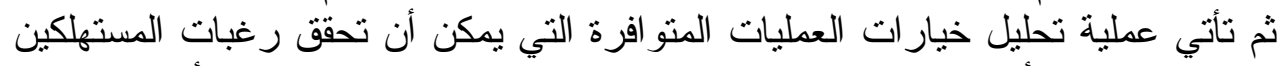

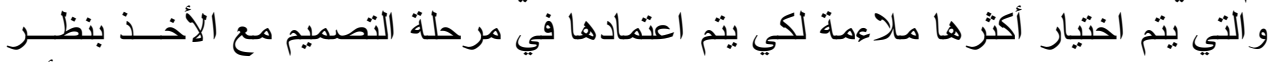

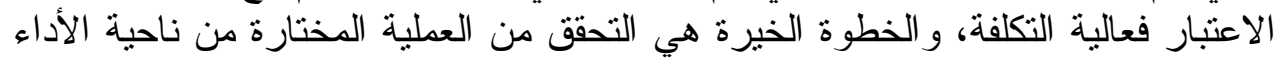
و الإمكانية لمقابلة رغبات المستهلكين المحددة. 


\section{اليامورן[ror}

(http://www.sixsigmaonline.org/articlelive/articles)

\section{المنافع المالية المتحققة نتيجة لتطبيق منهج الحيود السداسي}

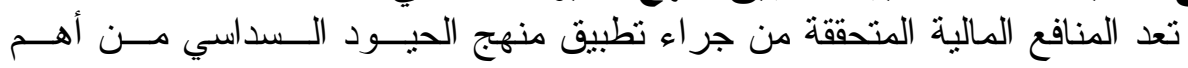

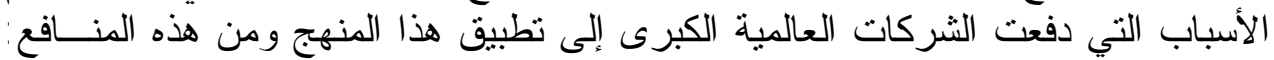

(www.isixsigma.com) 1. ب ارتقاع في مستويات الإير ادات. r r r تخفيض في الكلف التي تتحملها المنشأة من خلال تجنب الضر التبائ. r. r. تخفيض في كلف الفنّل. ع. ـ تخفيض في كلف إنتاج الوحدة الو احدة. ه. ارتفاع في القيمة السوقية للأسهم.

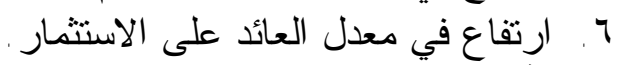
العلاقة بين كلف الفثل ومنهج الحيول العيود السداسي

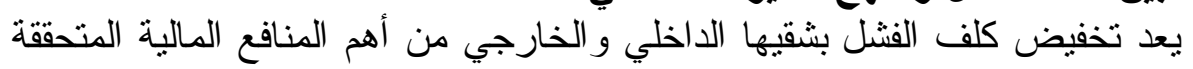

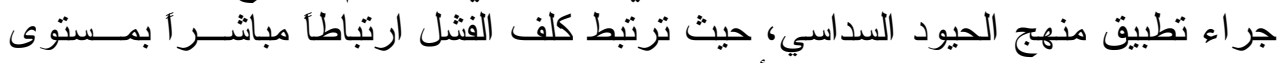

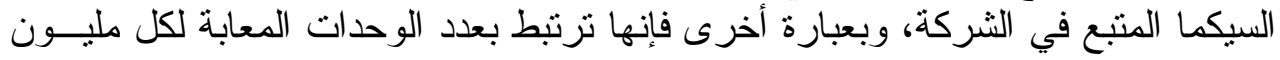

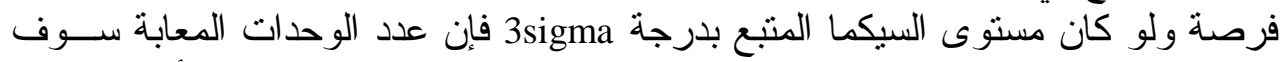

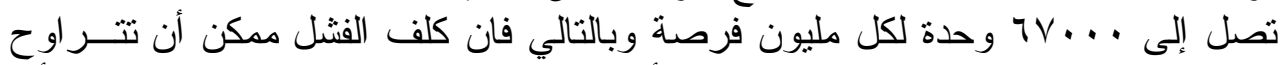

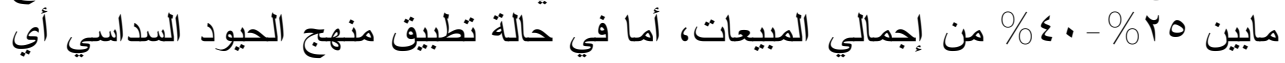

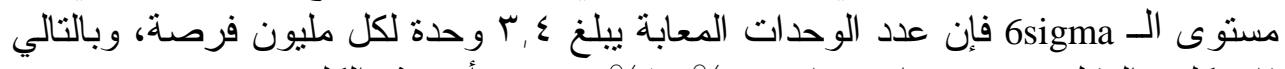

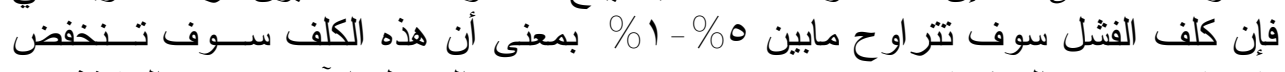

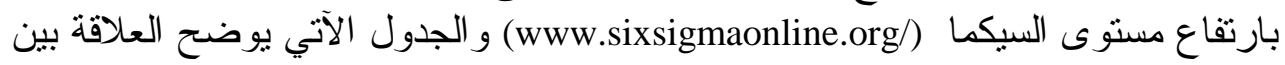
كلف الفنشل ومستوى السيكما المتبع في مواجهة العيوب.

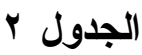

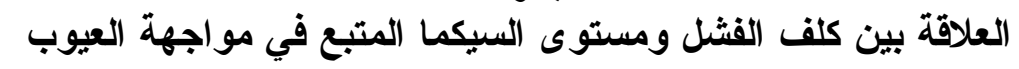

\begin{tabular}{|c|c|}
\hline نسبة كلف الجودة من اجمالي المبيعات & مستوى سيكما \\
\hline أكثر من ·ـ & $r$ \\
\hline 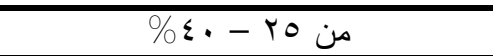 & $\Gamma$ \\
\hline \% من من 10-10 & $\varepsilon$ \\
\hline من 0-0 10\% & $\overline{0}$ \\
\hline$\% 1$ & 7 \\
\hline
\end{tabular}

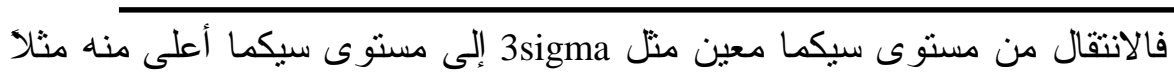

6sigma سيحقق الفو ائد الآتية (Kazmierski,1995,54)

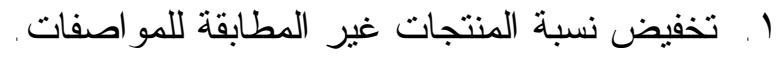

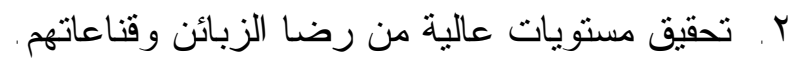
r. توفير فرص ملائمة لتخفيض كلف الفنشل. 


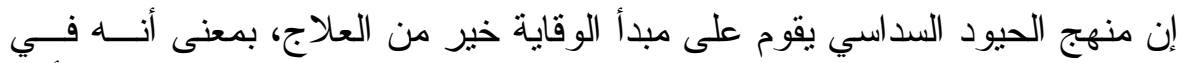

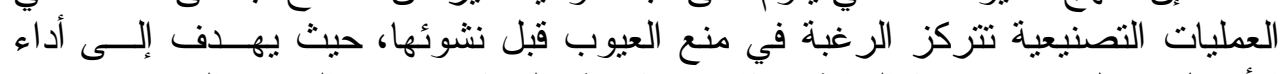

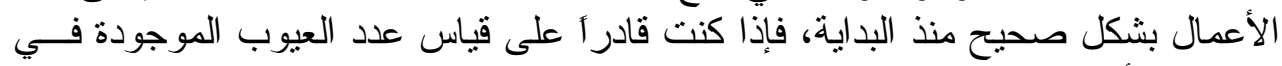

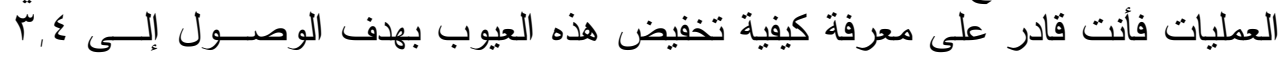

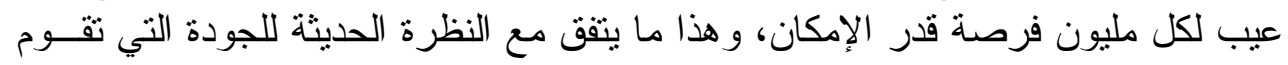

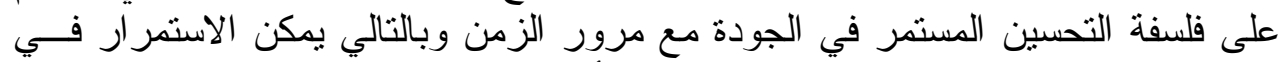

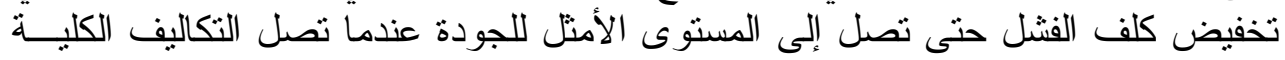

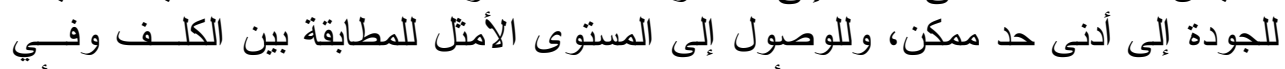

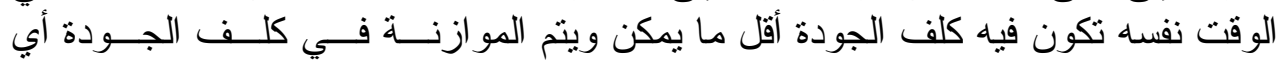

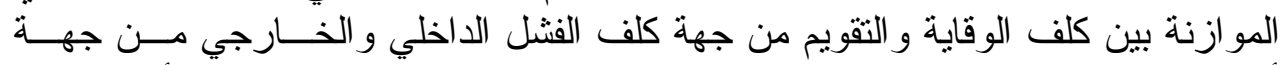

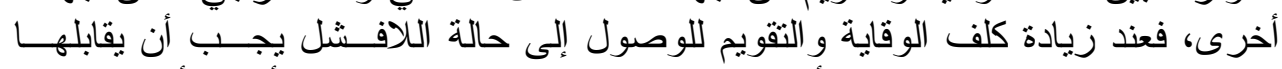

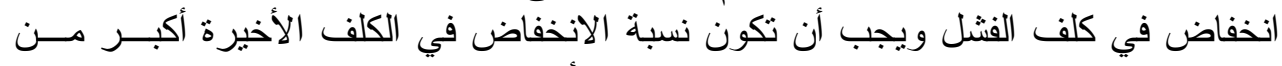

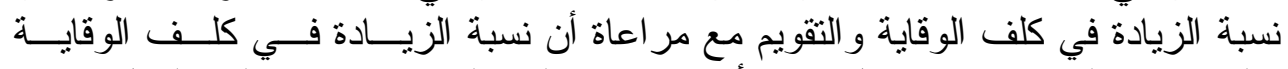

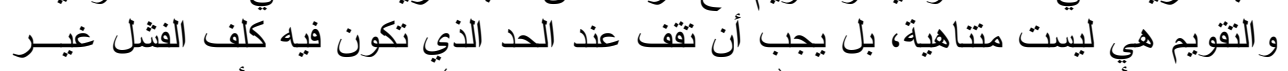

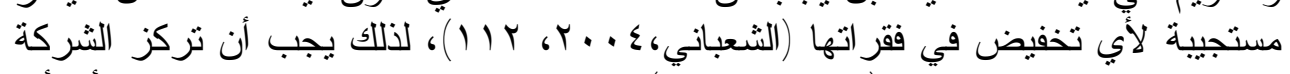

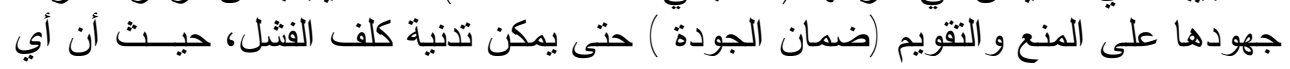

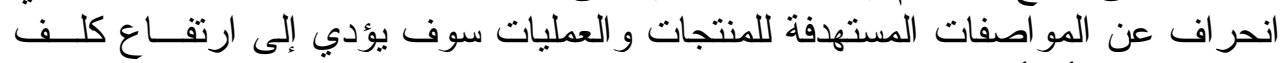

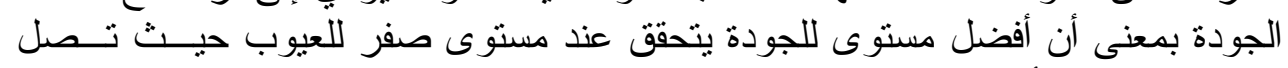

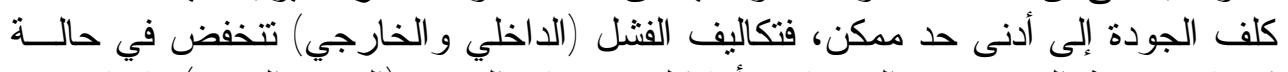

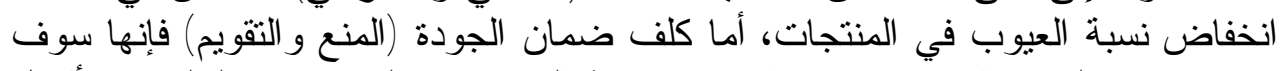

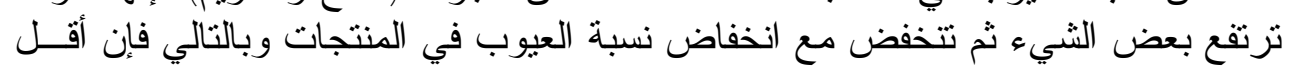

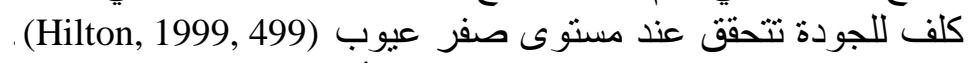

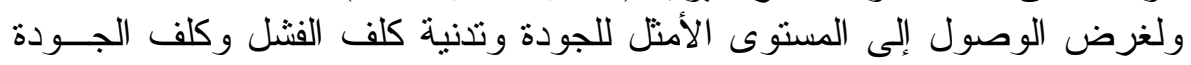

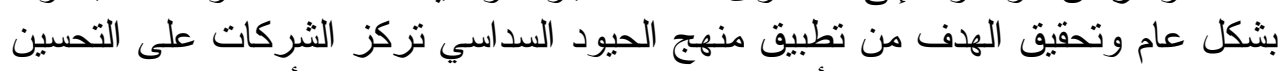

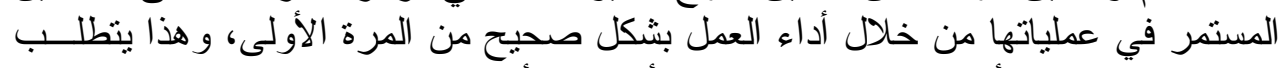

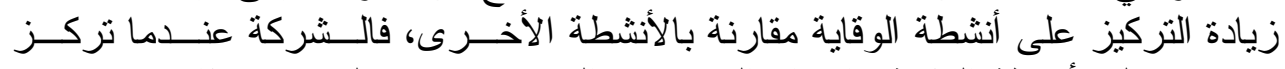

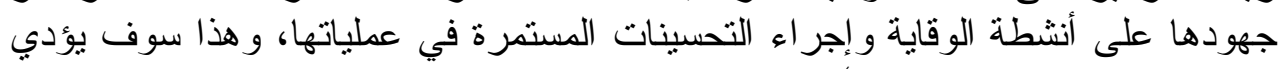
إلى (feigenbaum, 1991, 113):

1. زيادة كلف الوقاية بسبب التصميم الجيد للمنتج و استخدام بعض الأدوات الإحـــــائية

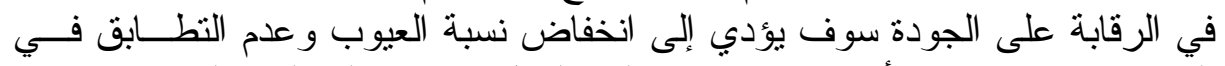

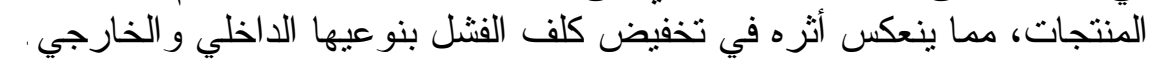

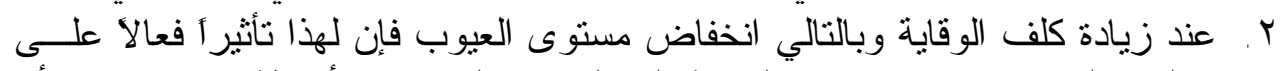

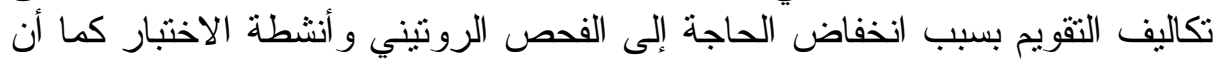

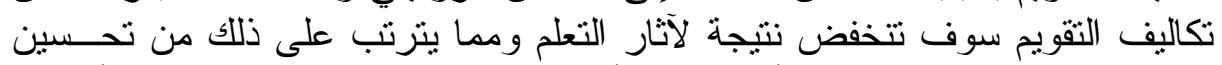

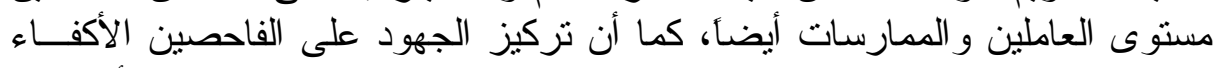
وتقليل عدد الفاحصين سوف يؤدي إلى تخفيض ايجابي في الكلف المرنبطة بأنسشة الفئة 


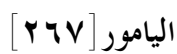

وبشكل عام فإن زيادة الإنفاق على أنشطة الوقاية يوفر عائدات مهمة على شـــل

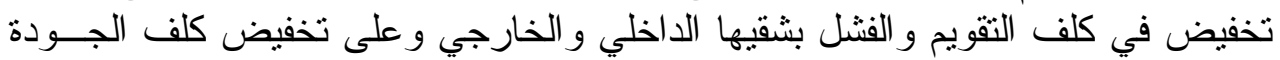

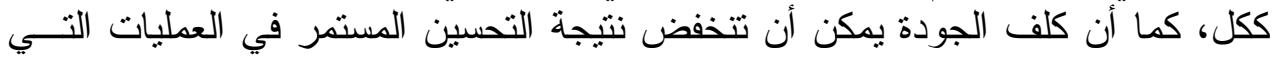

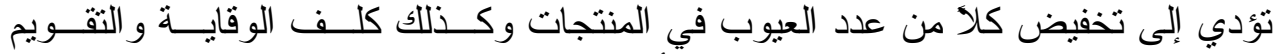
(Slack, et., al., 2004, 730)، لذلك ينبغي أن تعطي الإدارة الهتمامأ متز ايدا لكلف الوقاية، كائه

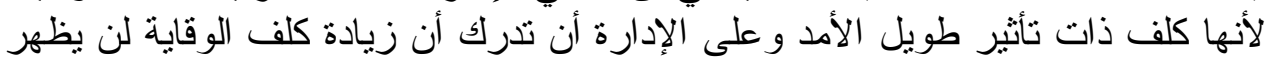

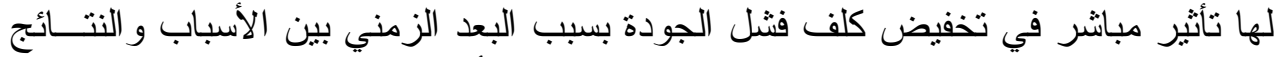

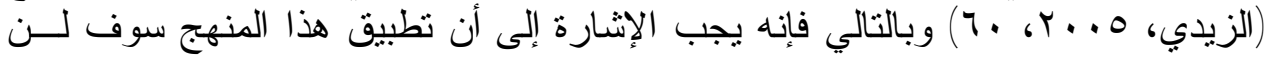

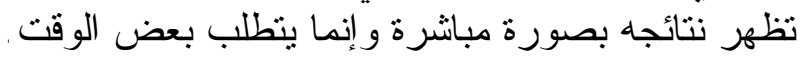

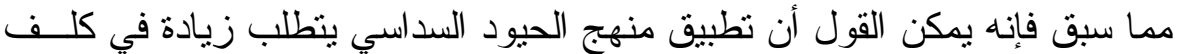

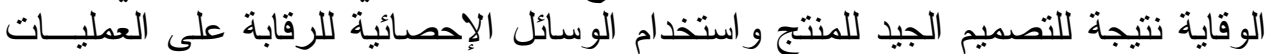

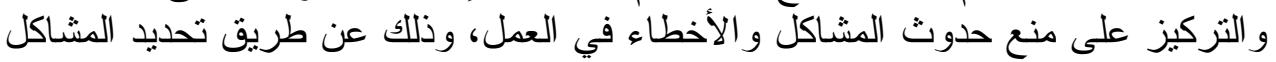

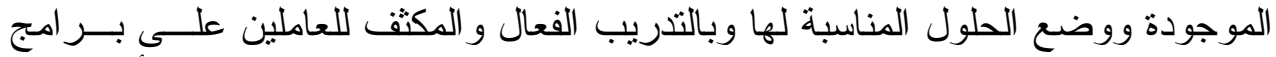

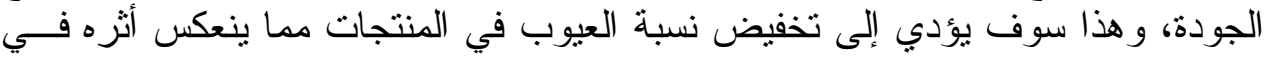

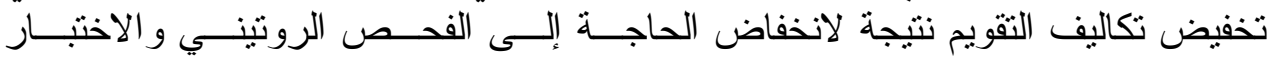
للمنتجات، كما أن كلف الفنشل سوف تتخفض وذللك لتخفيض تكاليف التلف وتكاليف إعادة

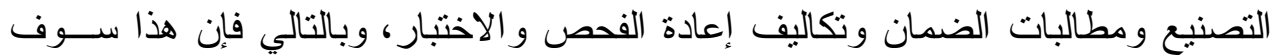
يؤدي إلى تخفيض في كلف الجودة بشكل إجمالي.

ثانياً - الجانب الميداني:دراسة حالة في معمل الألبسة الولادية في الموصل

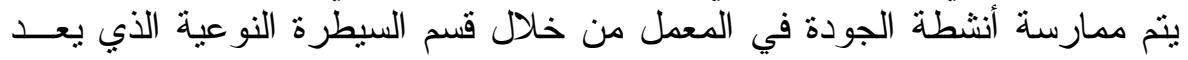

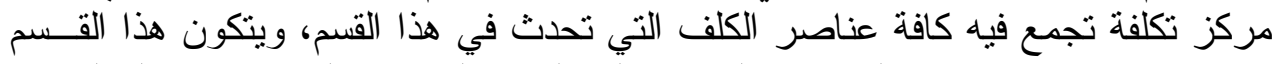

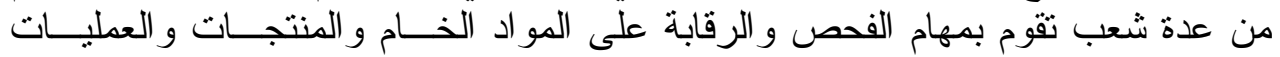

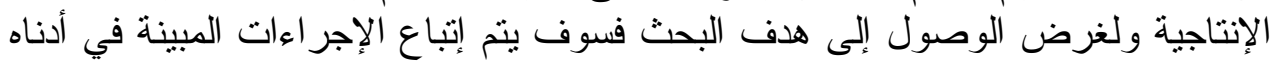

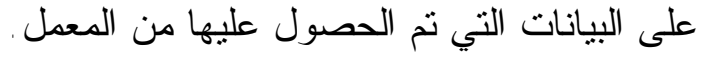

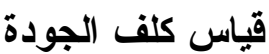

تم تحديد بنود و أنو اع كلف الجودة التالية في المعمل بالاعتماد على البيانات الفعلية

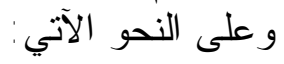

ا . تكاليف الوقاية التي تضمنت العناصر الآتية:

تأكيد ومر اقبة الجودة ونتمثل بالأجور المدفوعة للعاملين المستخدمة في تأكيد ورقابة العابة

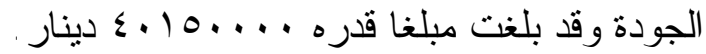

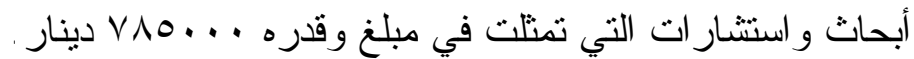

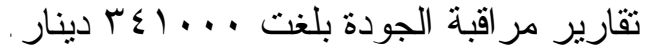

r ، تكاليف التقويم: وتتكون من البنود الآتية:

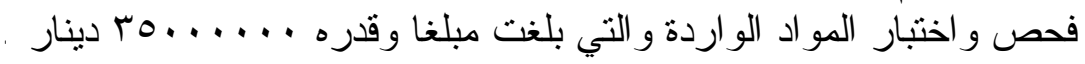

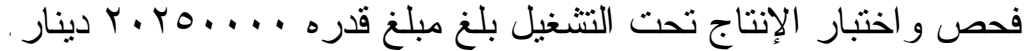

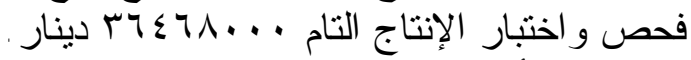

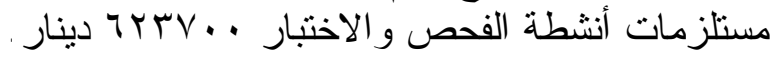




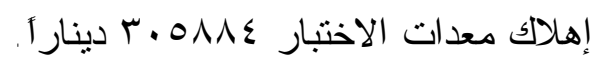

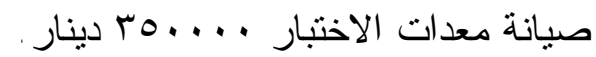

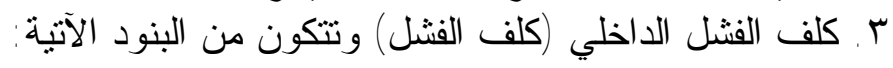

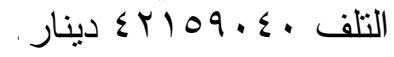

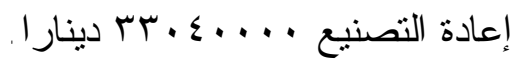

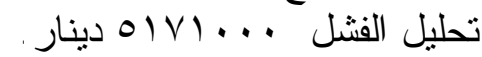

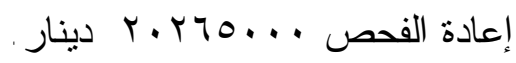

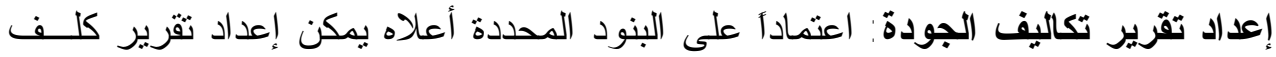

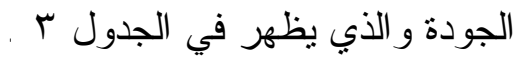

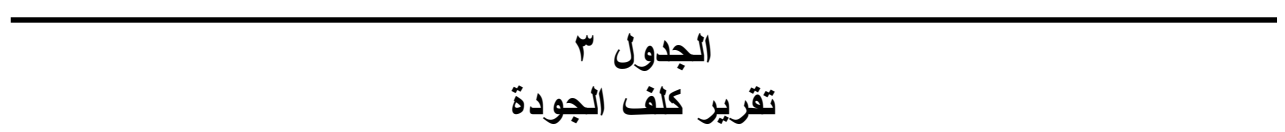

\begin{tabular}{|c|c|c|}
\hline النسبة إلى المبيعات & الكلفة & أنواع كلف الجودة \\
\hline & & أولاً- كلف الوقاية \\
\hline$\% \varepsilon, 7$. & $\varepsilon .10 \ldots$ & ت تأكيد ومر اقبة الجودة \\
\hline$\% \cdot, \cdot 9$ & $\vee \wedge 0 \ldots$ & أبحاث و استشنار ات \\
\hline$\% \cdot, \cdot \varepsilon$ & $r \varepsilon 1 \ldots$ & تقارير مر اقبة الجودة \\
\hline \multirow{3}{*}{$\% \varepsilon, V r$} & 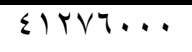 & المجموع \\
\hline & $\% \backslash \vee, O V$ & النسبة إلى المجموع الكلي لكلف الجودة \\
\hline & & ثُانياً- كلف التقويم \\
\hline$\% \varepsilon$ & ro...... & فحص و اختبار المو اد الو اردة \\
\hline \% Y,Tr & r.ro.... & فحص و اختبار الإنتاج تحت التتشغيل \\
\hline$\% \varepsilon, 1 \wedge$ & 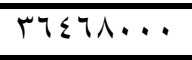 & فحص و اختبار الإتتاج التام \\
\hline$\% \cdot, \cdot \Lambda$ & TrTV.. & مستلزمات أنشطة الفحص و الاختبار \\
\hline$\% \cdot, \cdot \varepsilon$ & $r .01 \Lambda \Sigma$ & اندثار معدات الاختبار \\
\hline$\% \cdot, \cdot \varepsilon$ & ro.... & صيانة معدات الاختبار \\
\hline \multirow[t]{2}{*}{$\% 1 \cdot, 74$} & $9 Y 99 \vee 0 \wedge \varepsilon$ & المجموع \\
\hline & $\% r q, 01$ & النسبة إلى المجموع الكلي لكلف الجودة \\
\hline \multirow[t]{2}{*}{$\% 10, r 9$} & $T r \varepsilon r V T O \Lambda \varepsilon$ & كلف ضمان الجودة (كلف الوقاية+ كلف التقويم) \\
\hline & $0 V, 10$ & 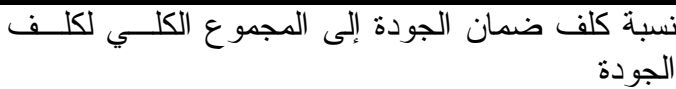 \\
\hline \multicolumn{3}{|r|}{ ثُالثاًُ- كلف الفشل الداخلي(كلف الفشل) } \\
\hline$\% \varepsilon, \wedge \varepsilon$ & $\varepsilon Y 109 \cdot \varepsilon \cdot$ & التلف \\
\hline 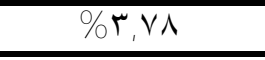 & $r \mu, \ldots \ldots$ & إعادة التصنيع \\
\hline$\% \cdot, 09$ & $01 \mathrm{N1} \ldots$ & تحليل الفشل \\
\hline$\%$ \%,rY & $r \cdot r 70 \ldots$ & إعادة الفحص \\
\hline \multirow[t]{2}{*}{$\% 11$, or } & $1 \ldots 7 r 0 . \varepsilon$ & المجموع \\
\hline & $\% \leqslant r, \wedge 0$ & النسبة إلى المجموع الكلي لكلف الجودة \\
\hline$\%$ \%V & $r r \leqslant q \cdot \wedge T r \varepsilon$ & مجمو ع كلف الجودة \\
\hline
\end{tabular}


من البيانات أعلاه بمكن القول أن كلف الوقاية شكلت أقل نسبة، إذ بلغـــت تقريبـاً

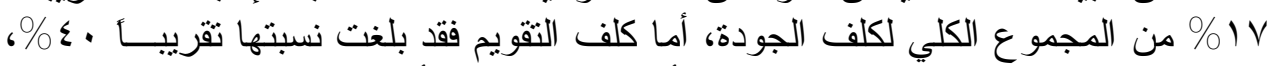

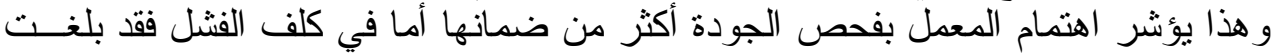

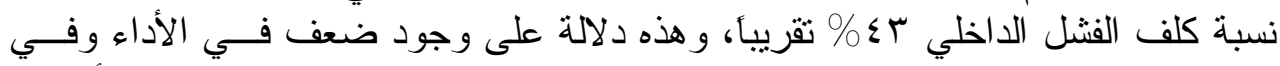

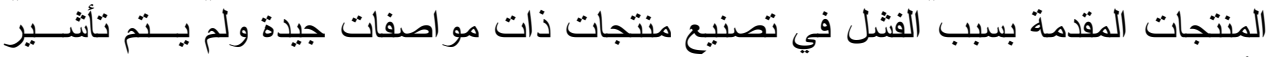

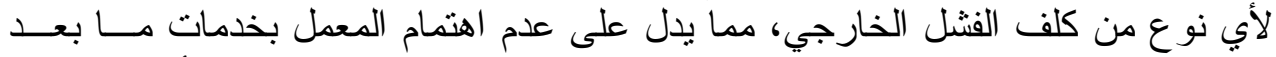

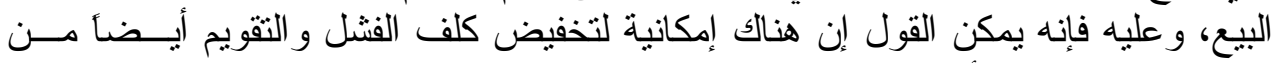
خلال التزكيز بشكل أكبر على كلف الوقاية لضئ لضمان الجودة.

\section{تحليد الأسباب الرئيسة لنشوء كلف الفثل}

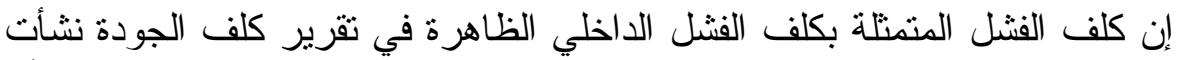

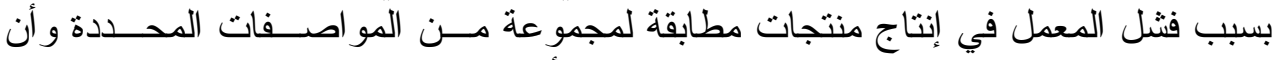

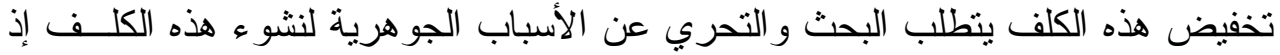

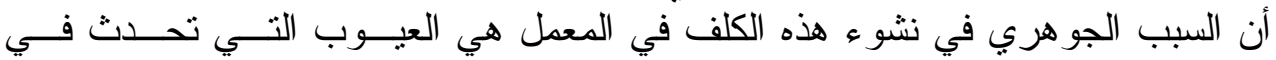

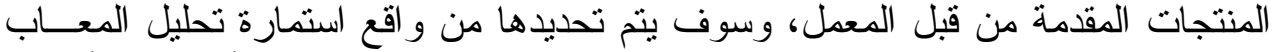

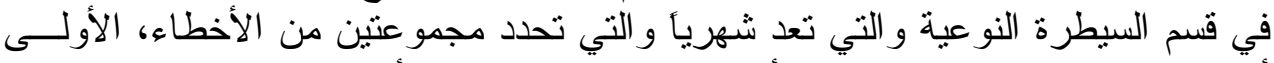

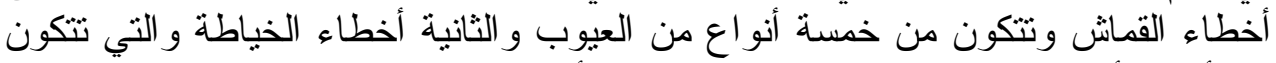

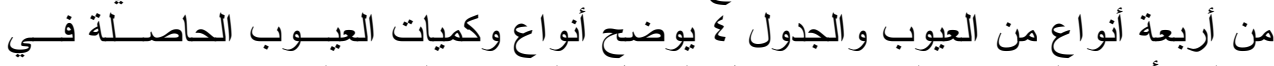

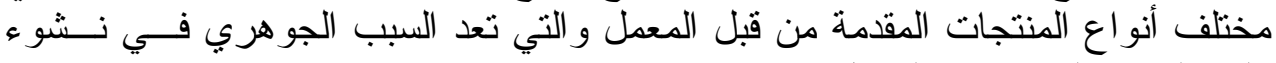

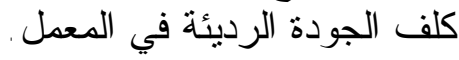

\begin{tabular}{|c|c|}
\hline \multicolumn{2}{|c|}{ 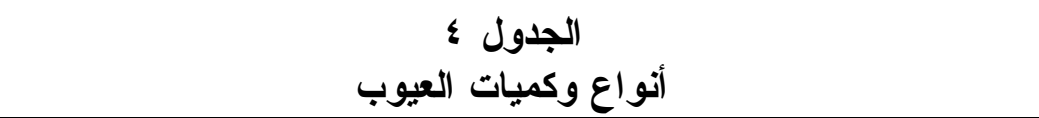 } \\
\hline كمية العيوب بالوحدات/لكل وحدة منتجة & أنواع العيوب \\
\hline & أولا - عيوب القماش \\
\hline tr. & تمزق ت تمز \\
\hline TO. & بقع \\
\hline$\varepsilon r \ldots$ & خطأ نسيجي \\
\hline$\Lambda T \cdot 0$ & تلون \\
\hline «). & تلوث \\
\hline ITTRO & المجموع \\
\hline كمية العيوب بالوحدات/لكل وحدة منتجة & أنواع العيوب \\
\hline & ثُانيا - عيوب الخياطة \\
\hline r... & تمزق بسبب الخياطة \\
\hline$r q \ldots$ & خطأ تتسيق \\
\hline rVo. & تلوث بسبب الخياطة \\
\hline V.. & قياسات غير مطابقة \\
\hline 940. & المجموع \\
\hline TYTAO & المجموع الكلي لأنو اع العيوب \\
\hline
\end{tabular}




\begin{tabular}{|c|c|}
\hline T.09YA & كمبة الإنتاج في سنة V... T \\
\hline$\% 11$ & النسبة إلى كمية الإنتاج \\
\hline
\end{tabular}

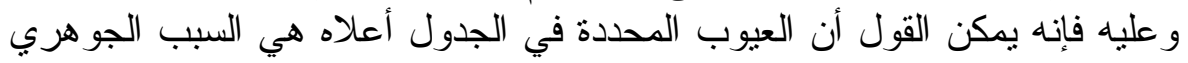

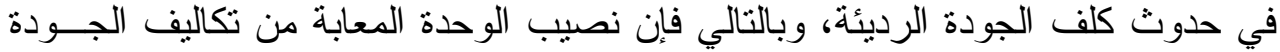
الرديئة يمكن تحديدها من خلال العلاقة الآتية:

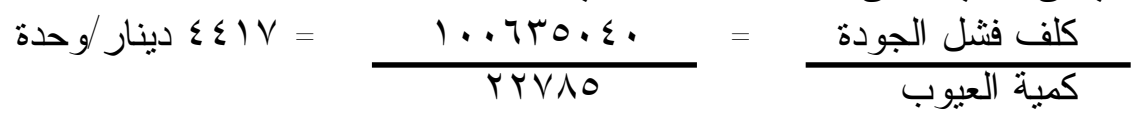

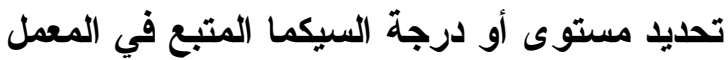

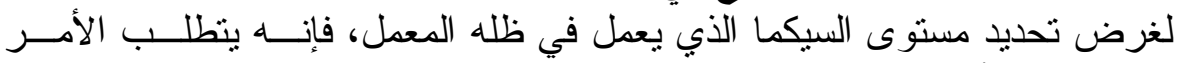

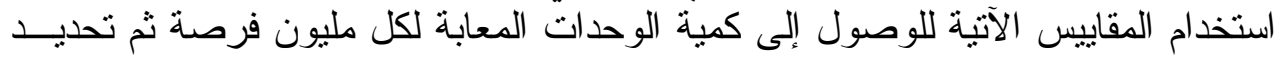

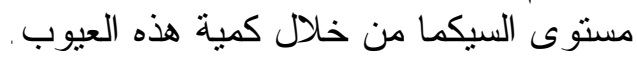

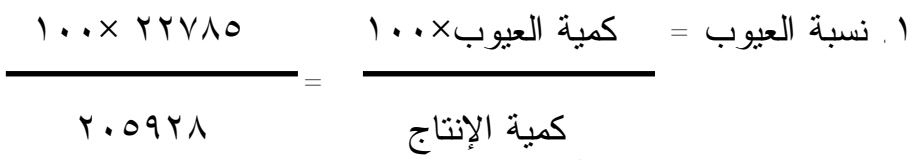

$$
\begin{aligned}
& \% 11=
\end{aligned}
$$

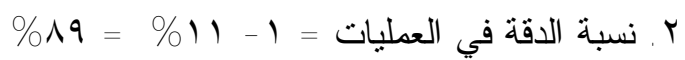

$$
\begin{aligned}
& \text { كمية العيوب }
\end{aligned}
$$$$
\text { كمية الإنتاج × عدد فرص ظهور العيوب (عدد أنو اع العيوب) }
$$$$
\cdot, \text { Rrrqr }=\frac{\text { rrVAO }}{9 \times r .09 r \wedge}=
$$

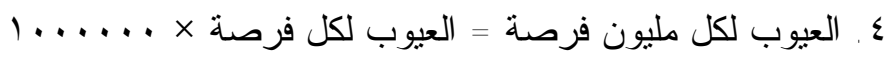

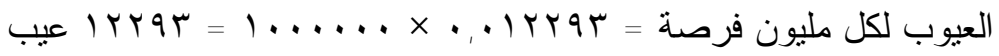

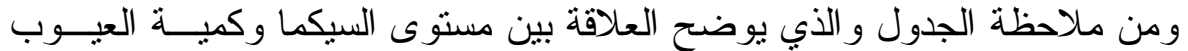

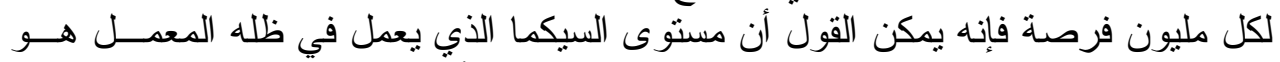

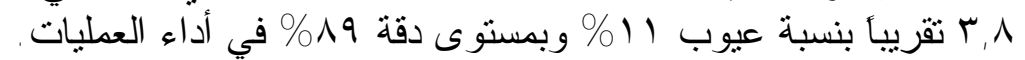

أثر رفع مستوى السيكما في المعمل في تخفيض كلف الفثل

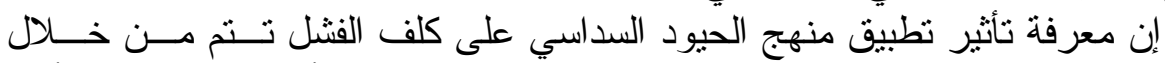

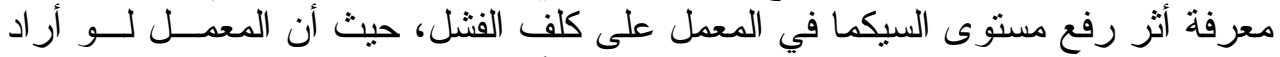

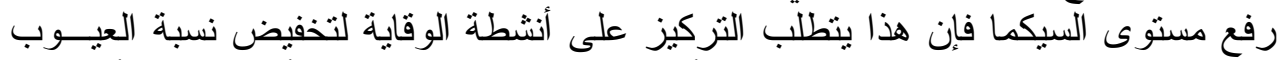

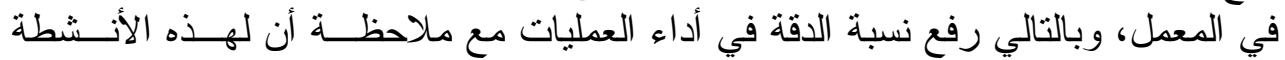

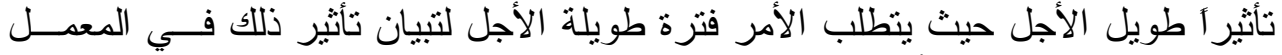

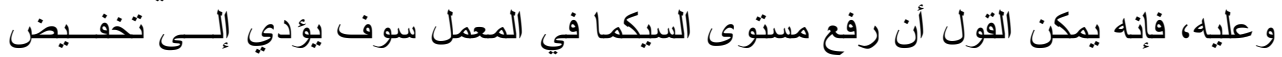

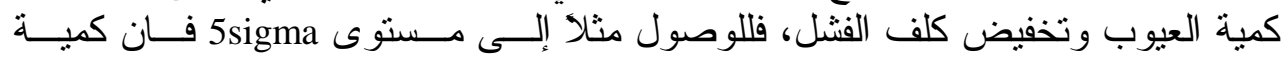


$[$ [rvi

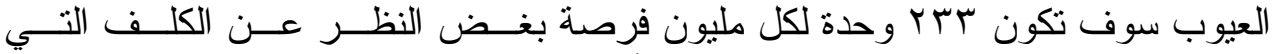

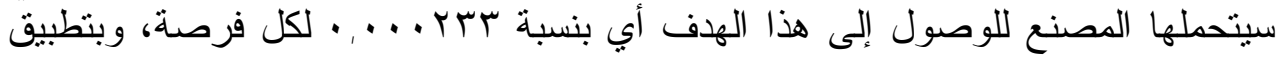
المعادلة في النقطة ب السابقة فإن كمية العيوب في المعمل سوف نكون:

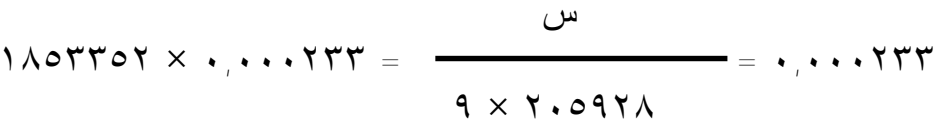

$$
\begin{aligned}
& \text { س = }
\end{aligned}
$$

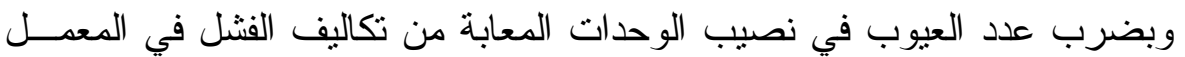

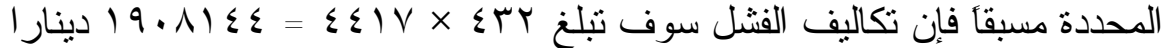

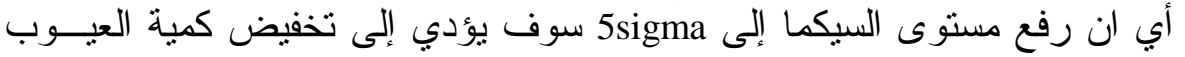

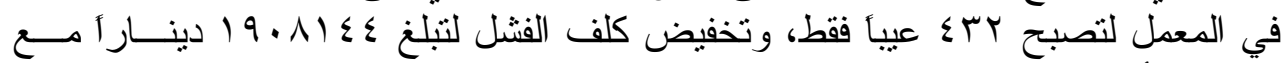

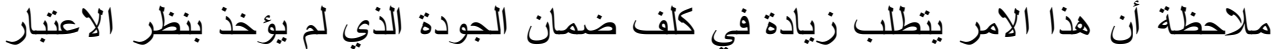

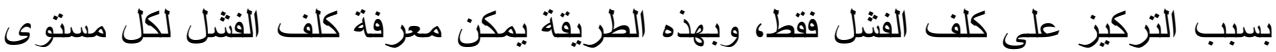

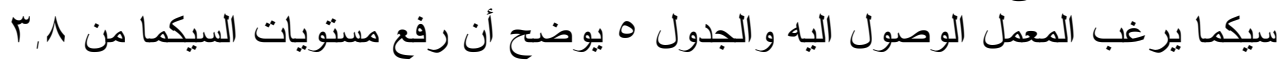
إلى مستويات أعلى سوف يؤدي إلى تخفيض كمية العيوب وتخفيض كلف رفي الفئل الفنل.

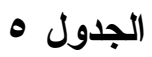

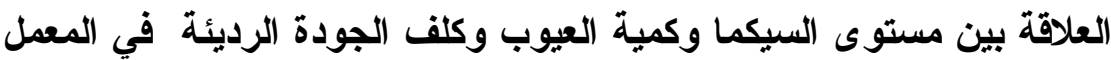

\begin{tabular}{|c|c|c|}
\hline كلف الفشل (دينار) & كمية العيوب (وحدة) & مستوى السيكما \\
\hline $11.01 \pi T \varepsilon$ & rO. & $\varepsilon, 0$ \\
\hline $19 \cdot 11 \leqslant \varepsilon$ & \&TY & 0 \\
\hline r70.r. & 7. & 0,0 \\
\hline$r .919$ & $\bar{v}$ & 7 \\
\hline
\end{tabular}

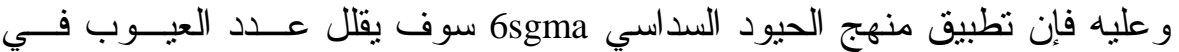

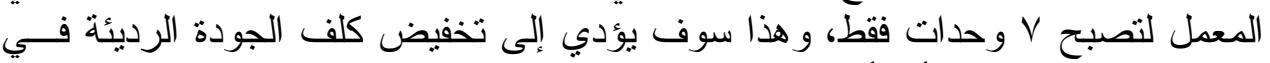

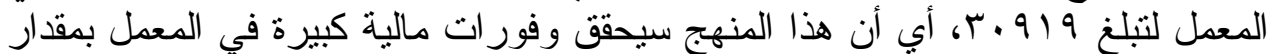

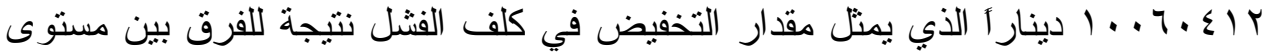

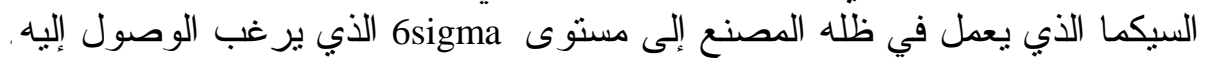

الاستنتاجات و التوصيات

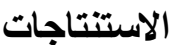

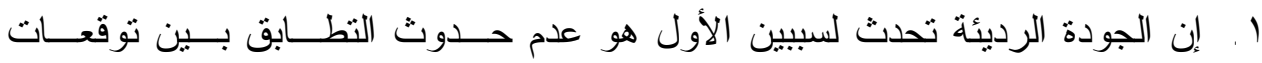

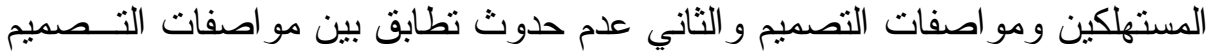

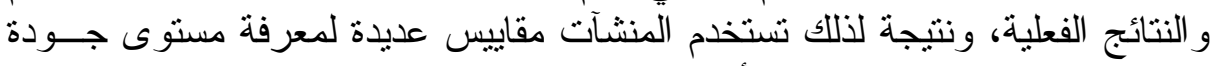
ما تقدمه من منتجات وخدمات و أهم هذه المقاييس نسبة الإنتاج المعاب كجـز ء عــن 
المليون، نسبة الإنتاج الجيد إلى إجمالي الإنتاج، التلف، المردودات، معدل العمليـات الو اقعة تحت رقابة الأدو ات الإنتاج الحصائية.

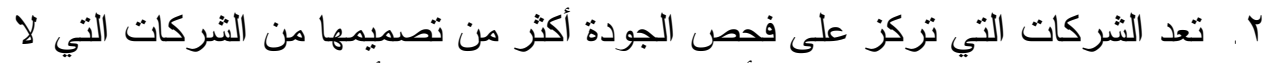

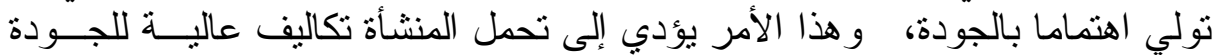

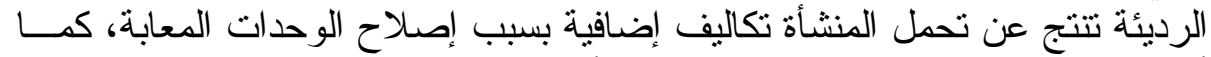

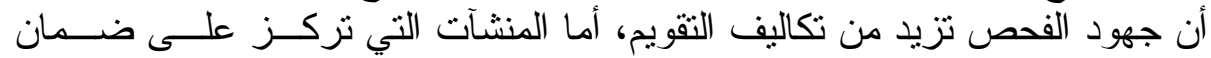
الجودة وتصميمها فإنها تتحمل تكاليف جودة أقلّ وذللك بسبب انخفاض كلف الجــــــات

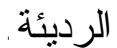

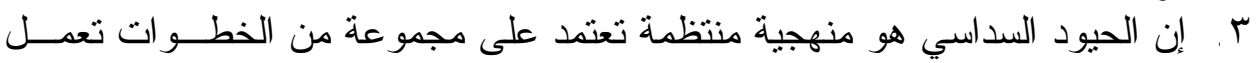
على تقليل الانحر افات وتحسين العمليات الإنتاجية من خلال استمر ار ضبط ونيط وتعـديل

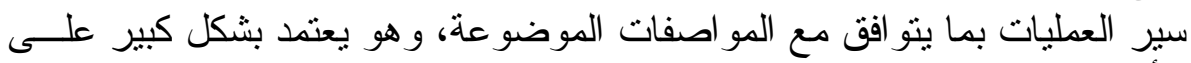

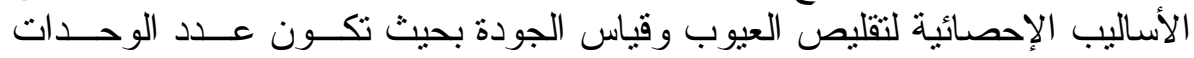

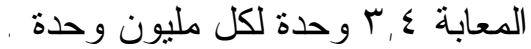

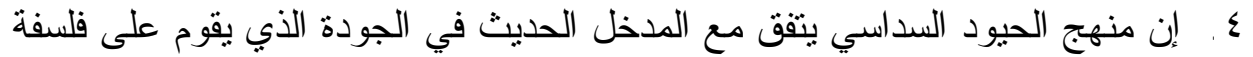

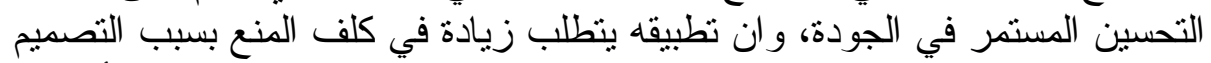

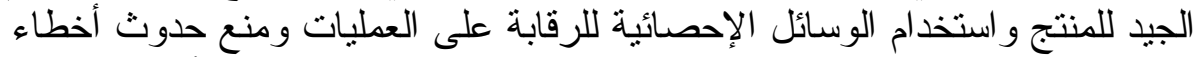

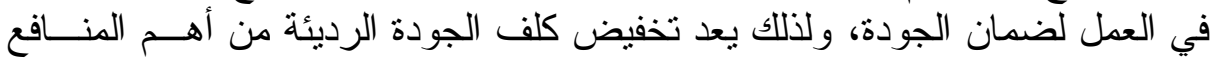

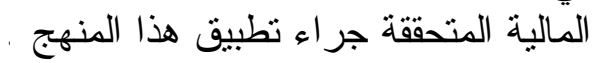

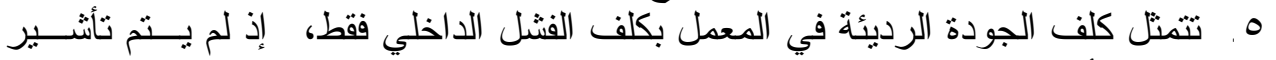

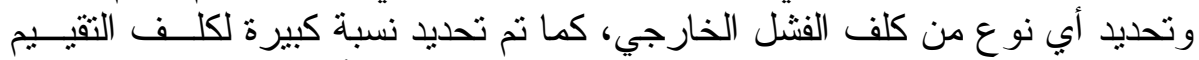

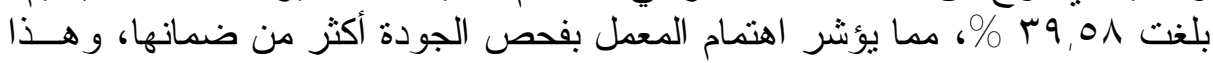

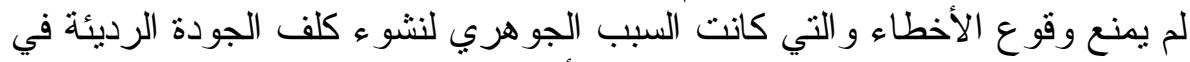

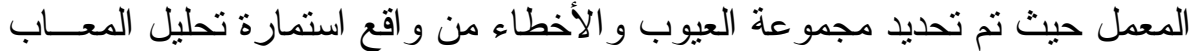

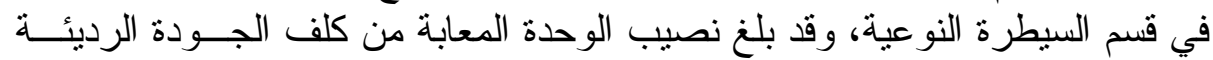

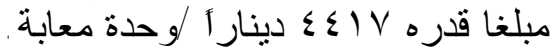

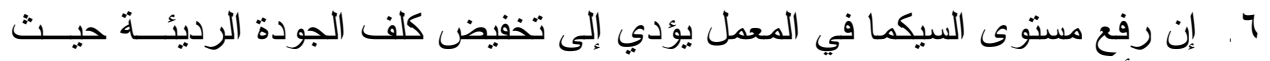

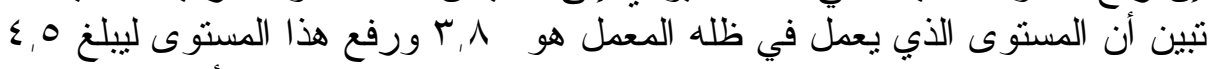

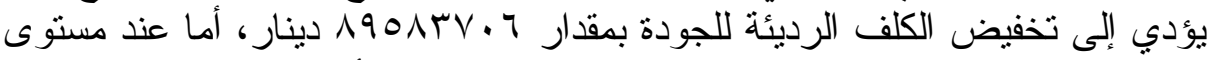

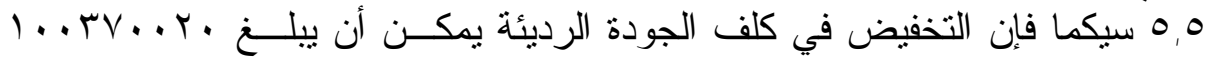

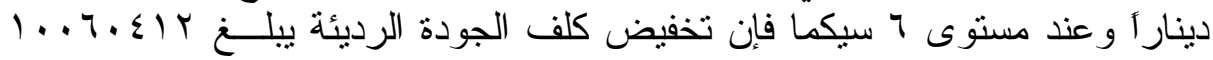

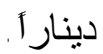

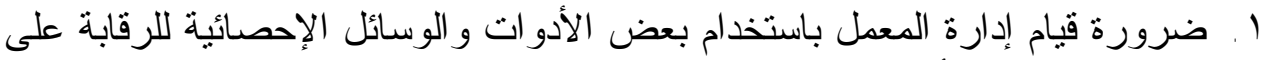

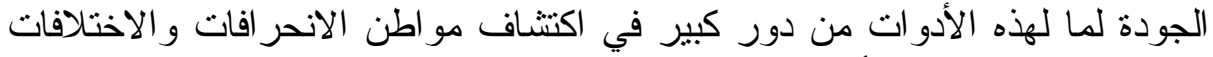
في الإنتاج و البحث عن أسبابها و اتخاذ الإجر اءوات الأب التصحيحية لمعالجنها. 


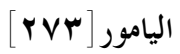

r. ضرورة اهتمام إدارة المعمل بتوفير معلومات عن كلف الجودة في المعمل من خلال الال

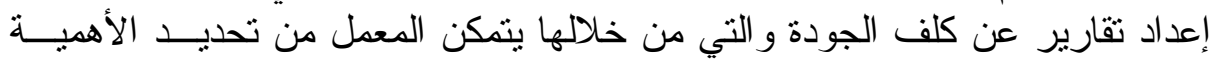
النسبية لمشاكل الجودة ومتابعة الأخطاء و اتخاذ الإجر اءوات التهات التصحيحية.

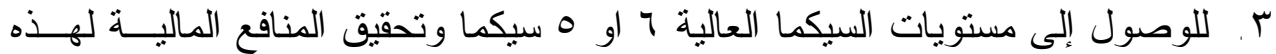

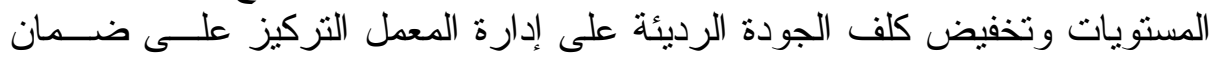

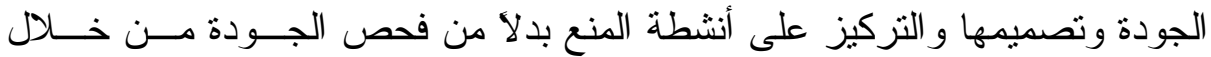

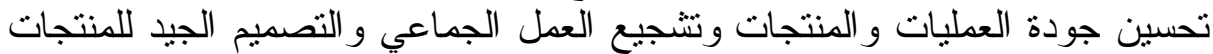

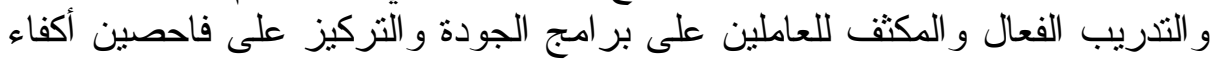

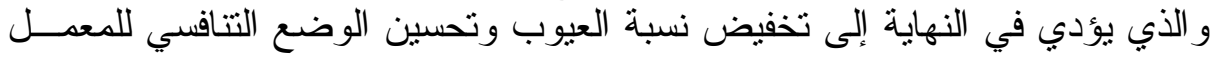

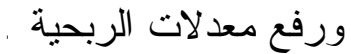

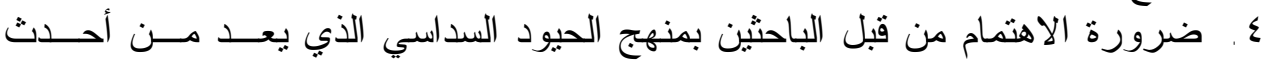

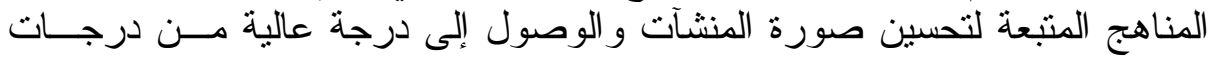

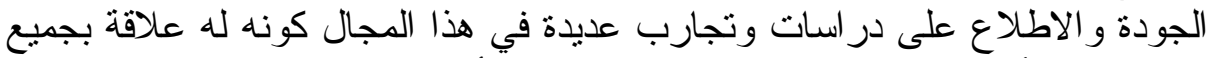

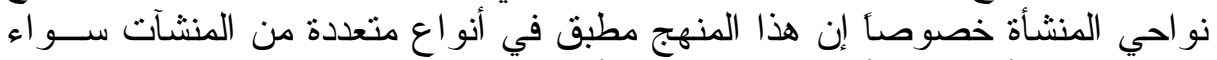

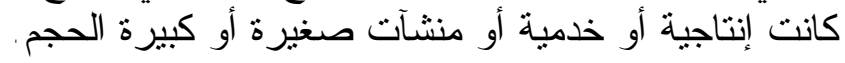

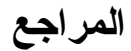 \\ أولاً - المراجع باجع باللغة العربية}

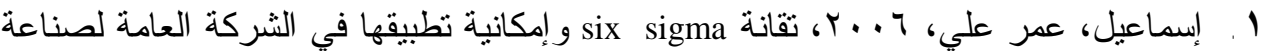

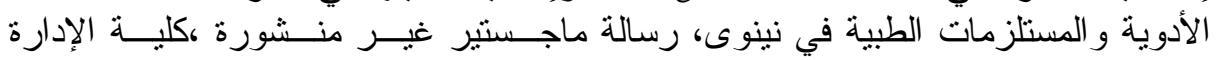

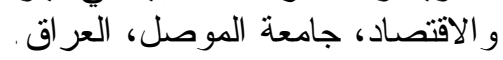

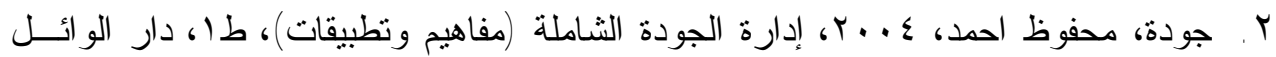

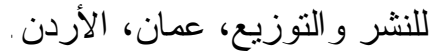
ץ. حسين، احمد حسين علي، ب . . r، المحاسبة الإدارية المتقدمة، الدار الجامعية، الإسكندرية،

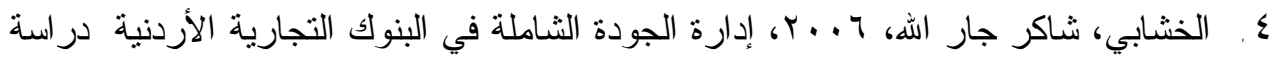

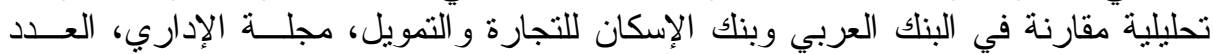

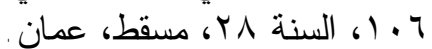

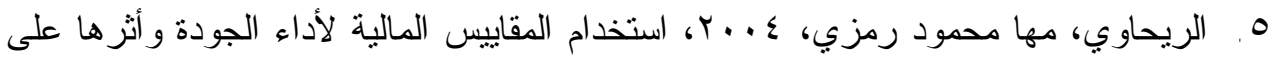

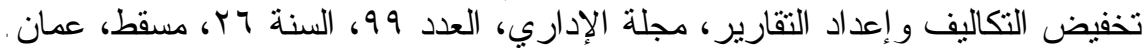

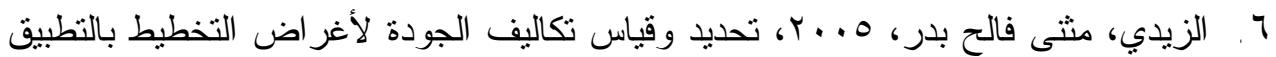

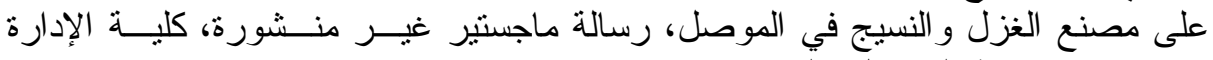

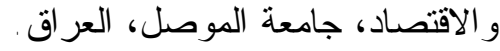

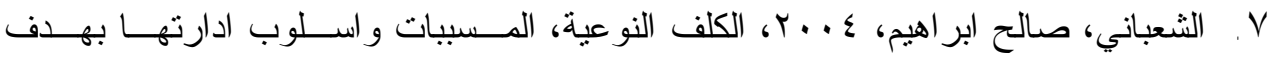

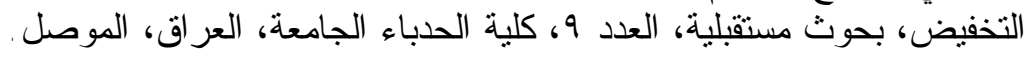

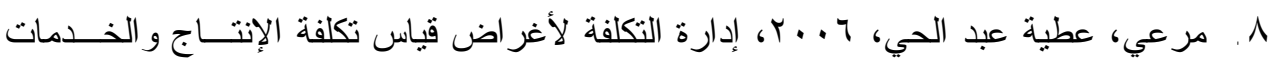

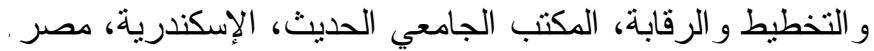

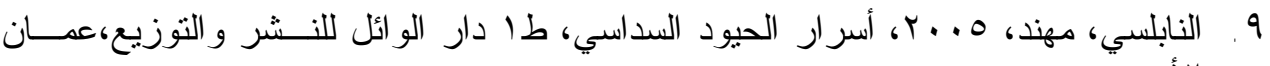

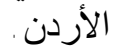




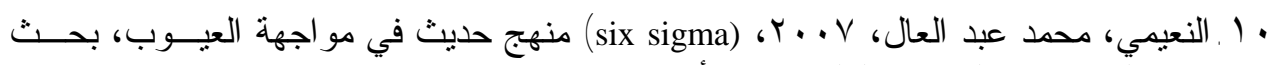

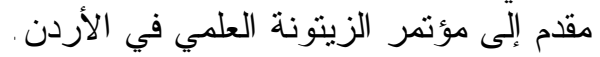

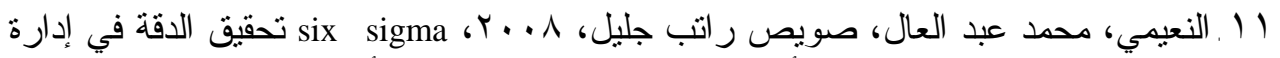

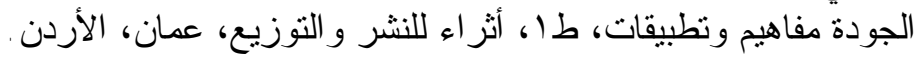

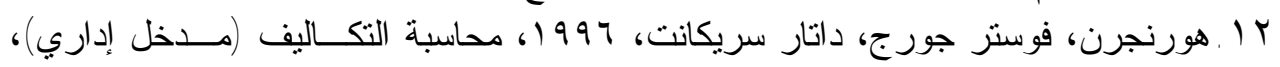
نزجمة احمد الحجاج، دار المريخ للنشر ، الرياض، دون، السعودية.

\section{ثانياً - المراجع باللغة الاكليزية}

1.Davis Mark m., aquilano Nicholas j., chase Richard b., 2003 , fundamentals of operations management, $4^{\text {th }}$ ed, mc graw-hill,inc, usa.

2. Davis mark m., heineke Janelle 2003, Managing services(using technology to create value), mc graw-hill,inc, usa.

3. Drury Colin, 2000, Manegment and cost Accounting, $5^{\mathrm{TH}}$,Edition, Business press ,UK.London.

4. Feigenbaum Armand v., 1991, total quality control, 3ed,mc graw-hill, inc, Singapore.

5. Hilton Rnald w.,1999,Managerial Accounting, $4^{\text {th }}$ ed, McGraw-Hill Companies inc, New York, USA.

6. Hilton Ronald w., Maher Michael w., Selto Frank H., 2000, cost management: strategies for business decisions, McGraw-Hill,USA.

7. Kaplan Roberet S., Atkinson Antony A. , 1998, Advanced Management Accounting, 3th ed, prentis hall, newjersey ,USA.

8. Schonberger richard j., knod,jr Edward m., 1997, operations management (customerfocused principles), 6ed, mc graw-hilll, inc, usa.

9. Slack Nigel, chambers stuart, Johnston Robert,2004, operations management, 4thed, prentice hall, England.

10. Thomas Kazmierski, j., 1995, ststistical problem solving in quality engineering, mc graw-hill, inc, usa.

www.arabicstat.com/forums

WWW.VRDS.COM/SIX SIGMA/DMAIC

www.realinnovation.com/content/c070319a.asp

www.sixsigmaonline.org/articlelive/articles

www.isixsigma.com 